\title{
ARTICLE
}

\section{Chromatographic Analysis of Byproducts from a Non-Toxic Ammunition and a Marked Ammunition: An Assessment of Toxicity}

\author{
Aline Marcelino Arouca ${ }^{\text {* }}$ (D) Maurício Leite Vieira² ${ }^{\text {ID }}$, Márcio Talhavini² ${ }^{\text {D }}$, Ingrid Távora \\ Weber ${ }^{3}$ iD \\ ${ }^{1}$ Instituto Federal de Brasília - IFB, Subcentro Leste, Complexo Boca da Mata, Lote 02, Samambaia Sul, $72302-$ \\ 300, Brasília, DF, Brazil \\ ${ }^{2}$ Instituto Nacional de Criminalística, Polícia Federal, SAIS Quadra 07 Lote 23, 70610-200, Brasília, DF, Brazil \\ ${ }^{3}$ Instituto de Química, Universidade de Brasília - UnB, P.O. Box 04478, 70904-970, Brasília, DF, Brazil
}

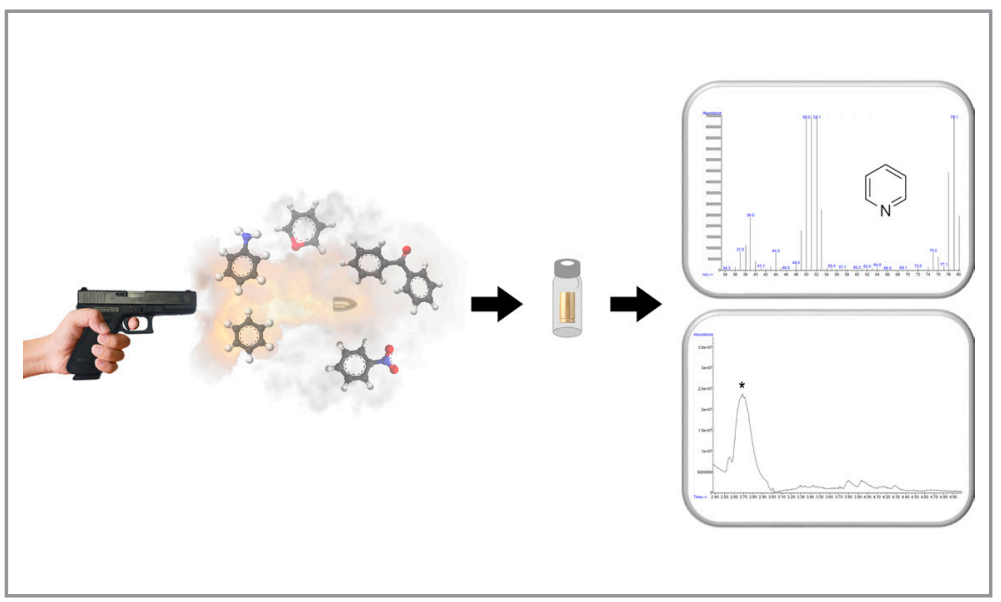

One way to access the toxicity of a fired ammunition is by analyzing the byproducts generated by shooting. This work has analyzed compounds produced by firing non-toxic ammunition (NTA) by Gas Chromatography-Mass Spectrometry (GCMS). In addition to standard NTA, NTA containing luminescent markers were also analyzed. Luminescent markers have been shown to be an excellent tool in the identification of Gunshot Residues (GSR) produced from NTA. As these markers are designed to tag NTA, they must not produce toxic byproducts. In this work, we focused on identification of volatile products that can be inhaled by shooter when firing and can represents risk to their health by acute and chronic exposition. For the NTA ammunition several toxic compounds, such as benzonitrile and naphthalene were found. They were related to de degradation of explosives, sensitizers, stabilizers, and other materials added to the gunpowder, indicating possible toxicity by shooters' long exposure. Moreover, as some of the compounds found are classified as GSR indicators, the used methodology could be adapted for GSR identification. Besides the compounds identified in NTA samples, in marked samples, pyridine and benzene were identified. Pyridine was provided by dipicolinic acid and benzene was provided by trimesic or terephthalic acid, all used as binder in the structures of the markers. However, it can be concluded that the possible toxicity of the NTA is mainly not altered by the presence of the markers because of the small amount of marker added to ammunition and because only a small part of the marker is degraded, requiring an unreal number of shots to produce some acute effect.

Cite: Arouca, A. M.; Vieira, M. L.; Talhavini, M.; Weber, I. T. Chromatographic Analysis of Byproducts from a Non-Toxic Ammunition and a Marked Ammunition: An Assessment of Toxicity. Braz. J. Anal. Chem., 2022, 9 (34), pp 138-161. doi: http:// dx.doi.org/10.30744/brjac.2179-3425.AR-34-2021 
Keywords: ammunition tagging, toxicity, non-toxic ammunition, luminescent marker, gas chromatography.

\section{INTRODUCTION}

The long-term exposure to gunshot residues (GSR) can be harmful to the health of frequent shooters, such as police and forensic experts, being the most known effect related to Pb-contamination [1]. After a series of studies [1-6] reported that frequent shooters had a high rate of lead in their blood, the ammunition industry developed heavy metals free ammunition (also called non-toxic ammunition, NTA). Despite the elimination of heavy metals represents an effective gain for the health of these professionals, the toxicity derived from other ammunition components, such as from degradation of the organic part of ammunition, has never been studied.

The GSR produced by NTA is hardly identified due to the lack of characteristic metals $(\mathrm{Pb}, \mathrm{Sb}$ and $\mathrm{Ba})$ or a unique chemical signature $[7,8]$. In fact, chemical markers are already being used for NTA in Germany [9]. In order to overcome this problem, luminescent markers has proven to be quite helpful in identifying the GSR and in analyzing the crime scene $[10,11]$. Interesting results were obtained using some Lanthanide Metal-Organic Frameworks (LMOFs) as luminescent markers in GSR. This materials exhibit chemical and optical signatures with high quantum yield and very defined emission spectra, which allow the unequivocal identification as LGSR (luminescent gunshot residues) by several nondestructive analytical methods [12].

In the last years a series of compounds [13-18] have been developed and tested in situations that simulated the routine analysis of forensic experts. The addition of luminescent markers to ammunition helped to identify the shooter, the weapon used, the location of the shooter and the distance at which the shot was fired [19-21], using only and UV lamp. Besides, LGSR was able to be visualized in different types of fabrics [22]. Furthermore, markers with different chemical and optical signatures can be used to mark specific batches of ammunition, allowing an ammunition coding system [23,24]. However, as the markers are intended primarily for NTA identification, luminescent markers are, naturally, expected to be non-toxic.

To access the toxicity of markers that could be used in NTA, Lucena et al. [25] evaluated the toxicity of the LMOF ${ }_{\infty}[\mathrm{Eu}(\mathrm{BTC})]$ by acute oral test (OECD \#432). This compound, that acted as an efficient luminescent marker in ammunition, was classified in the least toxic Globally Harmonized System (GHS) category (5), with a LD50 of $5000 \mathrm{mg} \mathrm{kg}^{-1}$, which strongly suggests a wide security range for its application [25]. Also, Talhari et al. [26] evaluated the acute oral and inhalation toxicity of the MOF ${ }_{\infty}[\mathrm{Eu}(\mathrm{DPA})(\mathrm{HDPA})]$ (OECD \#432 and \#436), another efficient luminescent marker for ammunition. Even when used in high doses ( $1 \mathrm{mg} \mathrm{L}^{-1}$ of air in the inhalation test and $2000 \mathrm{mg} \mathrm{kg}^{-1}$ of body weight in the oral test), the marker presented no toxic effect. Based on the acute oral test, it was also classified in GHS category 5 (which is the least toxic one), with a $\mathrm{LD}_{50}$ of $5000 \mathrm{mg} \mathrm{kg}^{-1}$ [26].

Although these markers have not been shown to be toxic, presenting a wide safety margin for oral and inhalation acute poisoning, all studies were conducted with markers itself, adapting some protocols usually related to drugs or biomaterials. Furthermore, since these markers are considered thermally and chemically stable, so far, no study has been carried out considering a possible degradation of part of the marker during the shot, as well as the possible byproducts of this degradation. In this way, additional studies are required to understand the toxicity aspects better, not only of the pure markers and of the LGSR generated by them, but also of the NTA-GSR itself, since the removal of heavy metals from NTA does not assures that toxic residues cannot be generated after the shot.

In this work, the byproducts found in cartridges of marked and non-marked NTA were studied. The byproducts are expected to derive from degradation of the gunpowder and stabilizers, and in the case of marked ammunition, from the degradation of the marker itself. With this, we expected to shed some light on possible toxic effects for frequent shooters due to continuous exposure to GSR as well as to investigate if the addition of Metal-Organic Framework (MOF)-based luminescent markers can alter the toxicity of the non-toxic ammunition (NTA). 


\section{MATERIALS AND METHODS \\ Luminescent markers}

The LMOFs used as luminescent markers were hydrothermally prepared, using a microwave reactor and autogenous pressure, with a maximum power of $400 \mathrm{~W}$ (Monowave 300 Anton Paar), as described by Arouca et al. [20]. The following markers were synthesized: EuDPA („[Eu(DPA)(HDPA)]), EuBDC $\left({ }_{\infty}\left[\mathrm{Eu}_{2}(\mathrm{BDC})_{3}\left(\mathrm{H}_{2} \mathrm{O}\right)_{2}\right]_{n}\right)$ and EuBTC $\left({ }_{\infty}[\mathrm{Eu}(\mathrm{BTC})]\right)$, as shown in Figure 1. Each marker was individually added to a sample of NTA gunpowder (Clean Rage, $\mathrm{CBC}^{\circledR}$ ) in the proportion of $10 \% \mathrm{wt}$, and ammunitions were reassembled for shots.

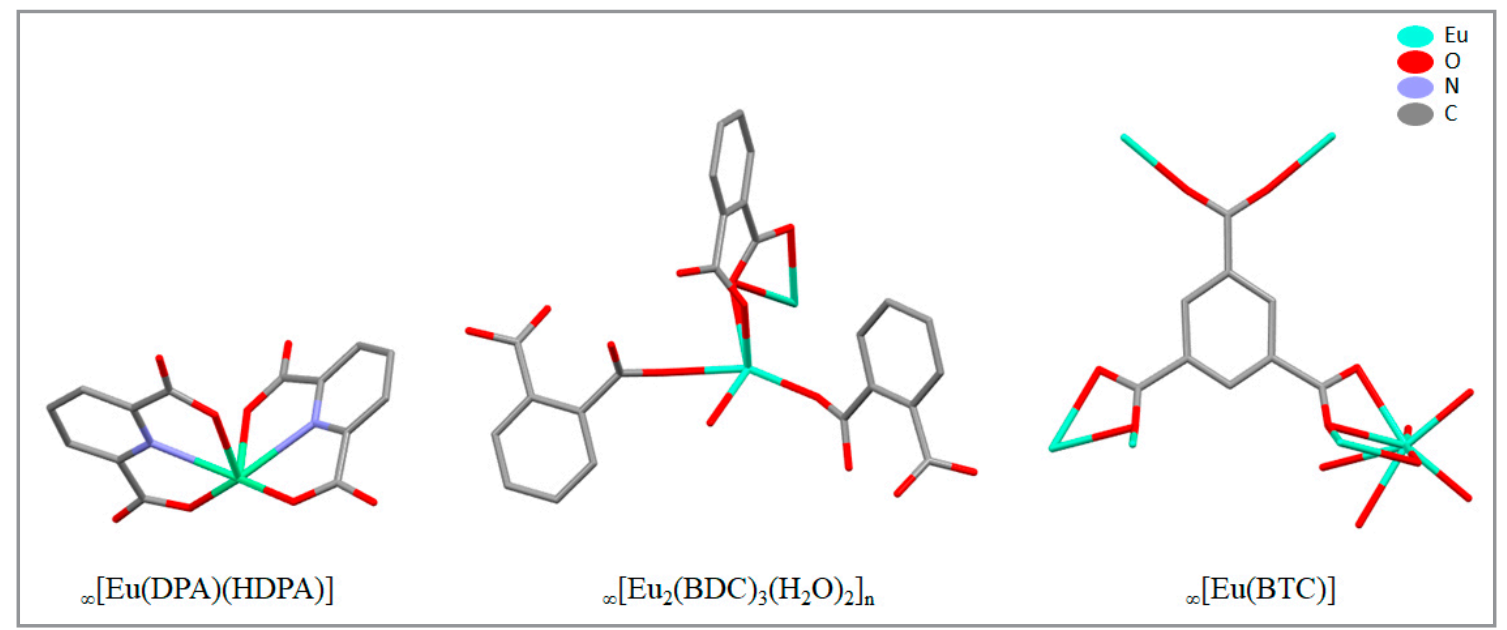

Figure 1. Asymmetric unit of the LMOFs: EuDPA, EuBDC and EuBTDC. The images were created using crystallographic information (CIF) from references [27-29], respectively.

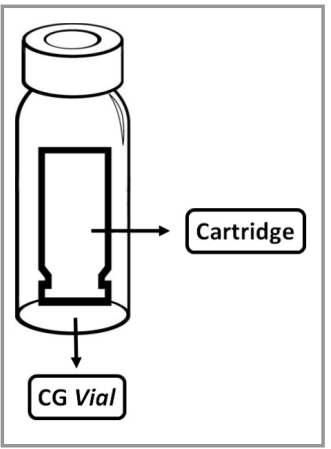

Figure 2. Scheme of a $9 \mathrm{~mm}$ cartridge in a GC vial to extract the volatile material after firing.

\section{Sample collection}

After shots, cartridges were immediately collected and kept in a $20 \mathrm{~mL}$ vial. The extraction of the volatile compounds was performed by headspace solid-phase microextraction (HS-SPME) using a $65 \mu \mathrm{m}$ PDMS/DVB fiber (SUPELCO), as shown in Figure 2. Samples were collected from a single fired cartridge of NTA and a cartridge of marked-NTA. The samples were analyzed by gas chromatography - mass spectrometry (GC-MS) fitted with a single quadrupole mass analyzer. Two samples (replicates \#1 and \#2) of each marked ammunition and the pure NTA ammunition were collected.

\section{SPME extraction}

The SPME extraction was carried out in this sequence: incubation at $80{ }^{\circ} \mathrm{C}$, at $600 \mathrm{rpm}$, for $3 \mathrm{~min}$. The equilibration time was $16 \mathrm{~min}$ and the desorption in the injector occurred for $20 \mathrm{~min}$.

\section{GC-MS condition}

The analyses were conducted using a mass spectrometer (Agilent model 5973), coupled to a gas chromatograph (Agilent model $6890 \mathrm{~N}$ ), with a phase capillary column poli(5\% diphenyl / 95\% dimethylsiloxane), dimensions $30 \mathrm{~m} \times 0.25 \mathrm{~mm} \times 0.25 \mu \mathrm{m}$ (Rtxi-5ms RESTEK), equipped with CTC PAL multipurpose sampler, with the SPME module.

The injector temperature was maintained at $280^{\circ} \mathrm{C}$, in Splitless mode with Split valve closed for 4 min. The column was maintained with a constant flow of Helium for $1.3 \mathrm{~mL} \mathrm{~min}^{-1}$. The chromatographic oven programming: initial temperature of $40{ }^{\circ} \mathrm{C}$, maintained for $1 \mathrm{~min}$ and then heated at a rate of $10{ }^{\circ} \mathrm{C} \mathrm{min}{ }^{-1}$ 
to $120{ }^{\circ} \mathrm{C}$, remaining at this temperature for $1 \mathrm{~min}$. Then the oven was heated at a rate of $5{ }^{\circ} \mathrm{C} \mathrm{min}^{-1}$ up to $180^{\circ} \mathrm{C}$, maintaining at this temperature for $1 \mathrm{~min}$, and finally, the oven was heated at a rate of $60^{\circ} \mathrm{C} \mathrm{min}{ }^{-1}$ to $315^{\circ} \mathrm{C}$, maintaining this temperature for $25 \mathrm{~min}$. The total analysis time was $50 \mathrm{~min}$ and 25 seconds.

The GC-MS interface was maintained at $280^{\circ} \mathrm{C}$, with the mass spectrometer operated in scan mode in the scan range from 30 to $500 \mathrm{~m} / \mathrm{z}$.

After the analysis, the chromatograms obtained for the marked ammunition were compared with those from NTA. Also, all mass spectra obtained at each chromatogram retention time were analyzed using the Chemstation Data Analysis program and the NIST Search program (version 2.0, NIST/EPA/NIH EI Mass Spectral Library).

Given the complexity of the matrix used (fired cartridge) and the fact that this is an exploratory study, we used only compounds that showed a match above $50 \%$ between the fragmentation pattern of the compound and the NIST data bank or those that were related to the degradation of the marker. For benzene and pyridine, standard solutions were used in other to determinate the retention time of each compound.

\section{RESULTS AND DISCUSSION NTA byproducts}

To identify the byproducts produced after the shot of an NTA, the mass spectra found in the chromatograms were compared with the NIST data base. A large variety of compounds were identified. These variations in the same ammunition type were already expected and can be associated with the complexity of the matrix and the volatility of some compounds present in the cartridges. Ammunition is not a homogeneous "sample", just as pistols are not precision instruments. So, changes in the "burning pattern" can be expected, resulting in the formation of different byproducts. In addition, small variations in the sampling time, ambient temperature, and humidity of the moment that the experiment was carried out can also lead to some variability in volatilization before the cartridge was placed in the vial. Despite this, some trends could be observed.

The following compounds were found in the pure NTA fired cartridge: glycidol (2.720-2.727 min), oxime-methoxy-phenyl (5.191 $\mathrm{min})$, benzonitrile (6.668 $\mathrm{min})$, naphthalene (9.992 $\mathrm{min})$, 2,6-di-tertbutylbenzoquinone (15.703 min), 2,4-ditert-butyl-6-nitrophenol (20.058-20.445 min), N,N'-diethyl-N,N'diphenylurea (24.059-24.452 $\mathrm{min}$ ), as shown in Figure 3. N,N'-diethyl-N,N'-diphenylurea is used as stabilizer in the gunpowder [30], and naphthalene has already been described in GSR [31]. The other compounds found can be related to de degradation of explosives, sensitizers, stabilizers, flash inhibitors, plasticizers and others materials added to the gunpowder [32]. 


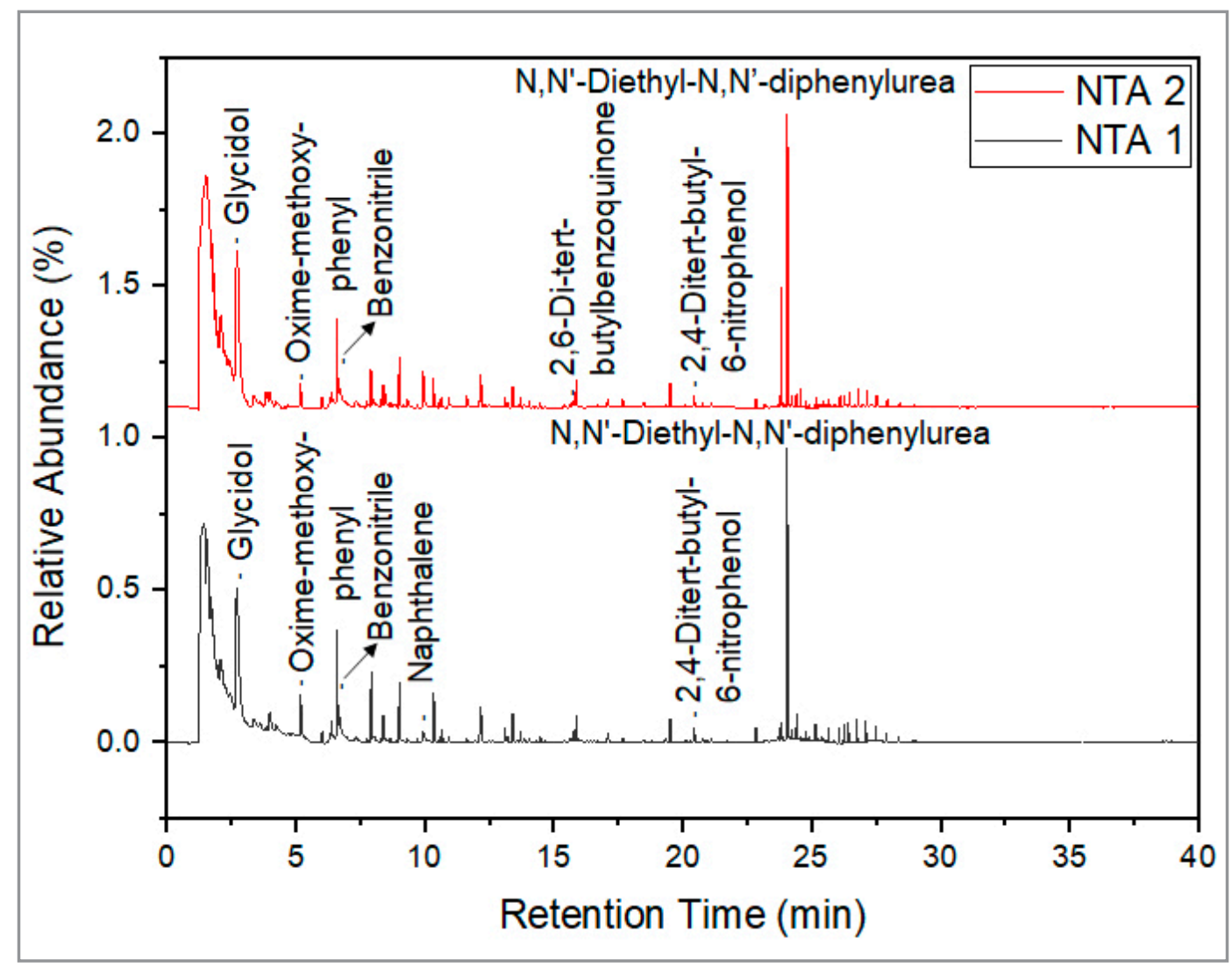

Figure 3. Chromatograms obtained from as-fired cartridge of pure NTA.

This result highlights an important aspect: despite being considered non-toxic, pure NTA also displays some hazardous byproducts after the shot. In fact, NTA is called as nontoxic ammunition because it is free from heavy metals. Nevertheless, it cannot be considered nontoxic because it produces some organic compounds that have known toxic effects. One of these compound found is naphthalene, a bicyclic aromatic hydrocarbon that is classified as Category 2B for as Carcinogenicity (possibly carcinogenic to humans) [33]. Carcinogenicity have been seen in rats studies, in which nasal tumors and non-neoplastic inflammatory changes has been identified [34]. In humans, naphthalene can cause hemolytic anemia with associated jaundice and cataract formation [34]. Also, form an acute exposure, hemolytic anemia and cataracts were observed [35].

Another compound found was benzonitrile. In humans, it was reported to cause severe respiratory distress, tonic convulsions, and periods of unconsciousness [36]. In animals, toxicity data are lethality and non-lethal effects in rats, mice, and rabbits [37].

Several other compounds are described as organic GSR by Goudsmits et al. [32], such as pyrene and anthracene, polycyclic aromatic hydrocarbons (PAH) classified as 3 and 2B, respectively, as well as benzyl nitrile, which have known toxic effects. Despite the presence of notoriously hazardous compounds derived from degradation of organic part of ammunition, a study about the toxicity of the organic GSR from both NTA or conventional ammunition (as was done with the Pb/Ba particles of the inorganic GSR) has not yet been carried out. The presence of the compounds listed above in the GSR may indicate that chronic exposure to vapors resulting from the firing of a NTA ammunition can produce toxic effects, requiring further studies. 


\section{LGSR byproducts}

The study was focused on three previously studied MOF-based markers, in order to identify the presence of benzene in trimesic acid $\left(\mathrm{H}_{3} \mathrm{BTC}\right)$ and in terephthalic acid $\left(\mathrm{H}_{2} \mathrm{BDC}\right)$; or pyridine structures, in dipicolinic acid $\left(\mathrm{H}_{3} \mathrm{DPA}\right)$. These three compounds $\left(\mathrm{H}_{3} \mathrm{BTC}, \mathrm{H}_{2} \mathrm{BDC}\right.$ and $\left.\mathrm{H}_{3} \mathrm{DPA}\right)$ are used as ligands (now on called BTC, BDC and DPA) to build up the LMOF structure (Figure 4). It is important to point out that these three markers have been studied before and have demonstrated potential as luminescent markers in ammunition (conventional and NTA) $[19,20,24]$. Moreover, EuBTC and EuDPA have been evaluated by oral or inhalation acute tests and shown as not harmful $[25,26]$.

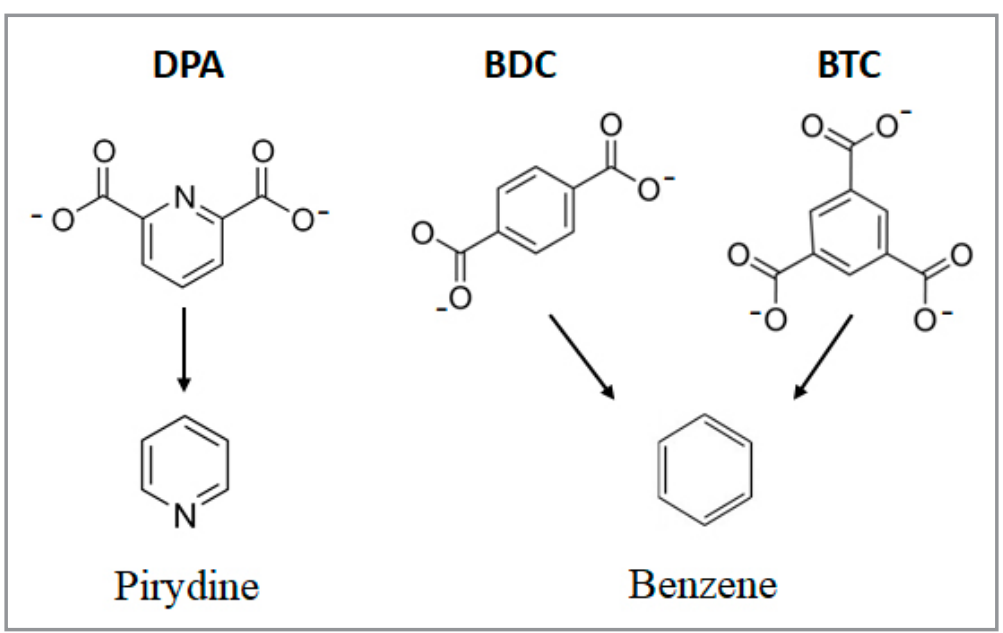

Figure 4. Ligands present in structures of tested markers and target byproducts.

For GSR-NTA marked with EuDPA, it was possible to observe, at 3.002-3.015 min, a peak referring to pyridine, as pointed in Figure 5. Also, less intense peaks corresponding to the following compounds were found: 2,4,7,9-tetramethyl-5-decyne-4,7-diol (14.357-14.362 min), 6-tert-butyl-4-ethyl-1,1-dimethylindan (19.155-19.156 $\mathrm{min})$ and 7,9-di-tert-butyl-1-oxaspiro(4,5)deca-6,9-diene-2,8-dione (24.104 min). Their structures are shown in Figure 6. Other compounds found in the NTA, such as N,N'-Diethyl-N,N'diphenylurea and glycidol, were also found in the EuDPA's chromatograms. 


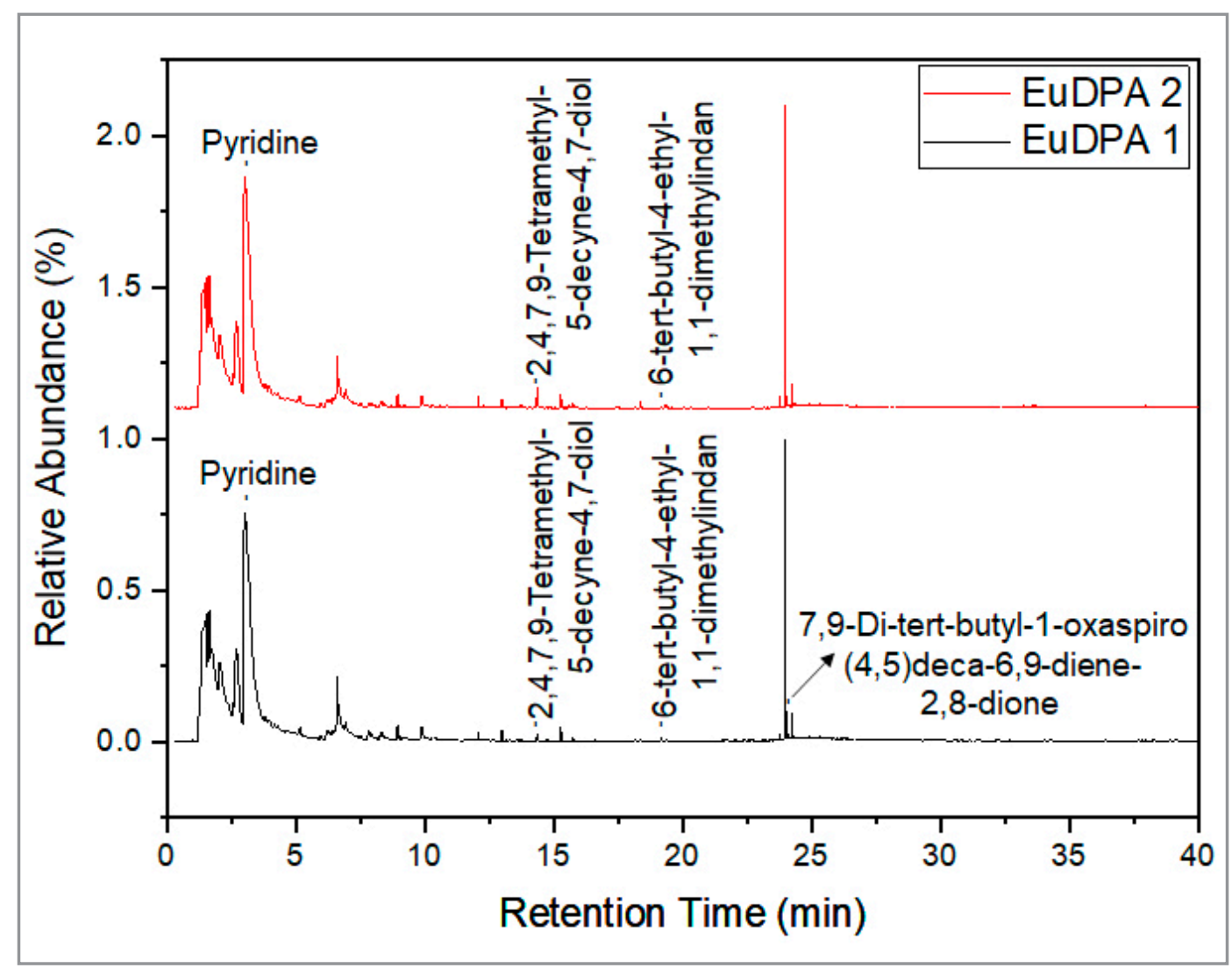

Figure 5. Chromatograms obtained from as-fired cartridge of NTA marked with EuDPA.<smiles>c1ccncc1</smiles>

Pyridine<smiles>CCc1cc(C(C)(C)C)cc2c1CCC2(C)C</smiles>

6-tert-butyl-4-ethyl-1,1dimethylindan

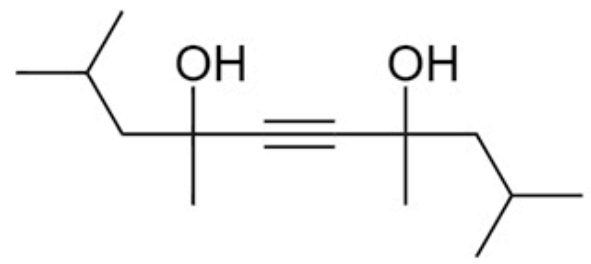

2,4,7,9-Tetramethyl-5-decyn-4,7-diol<smiles>CC(C)(C)C1=CC2(C=C(C(C)(C)C)C1=O)CCC(=O)O2</smiles>

7,9-Di-tert-butyl-1oxaspiro(4,5)deca-6,9-diene-2,8dione

Figure 6. Structures of compounds found in NTA-GSR marked with EuDPA. 
For GSR-NTA marked with EuBDC and EuBTC, a peak corresponding to benzene was observed at 2.231-2.248 min (Figure 7) and 2.260-2.268 min (Figure 8), respectively. Moreover, for GSR marked with EuBDC, the following compounds were found: alfa-methylbenzeneethanamine (3.298 min), benzaldehyde (6.235 min), nitrobenzene (8.244-8.249 min), biphenyl (13.820-13.872 min), acenaphthylene (15.346$15.347 \mathrm{~min})$, dibenzofuran (16.833-16.834 $\mathrm{min}$ ) and benzophenone (19.255-19.258 min). While for GSR-NTA marked with EuBTC, the listed compounds were found: 3-(3-Carboxy-4-hydroxyphenyl)-dalanine (5.121 $\mathrm{min})$, benzaldehyde (6.237 $\mathrm{min})$, phenol (6.460 min), biphenyl (13.809-13.813 min) and acenaphthylene (15.347 $\mathrm{min})$. All structures are shown in Figure 9. Again, the compounds found for the pure NTA ammunition were also found for the EuBDC and EuBTC marked GSR.

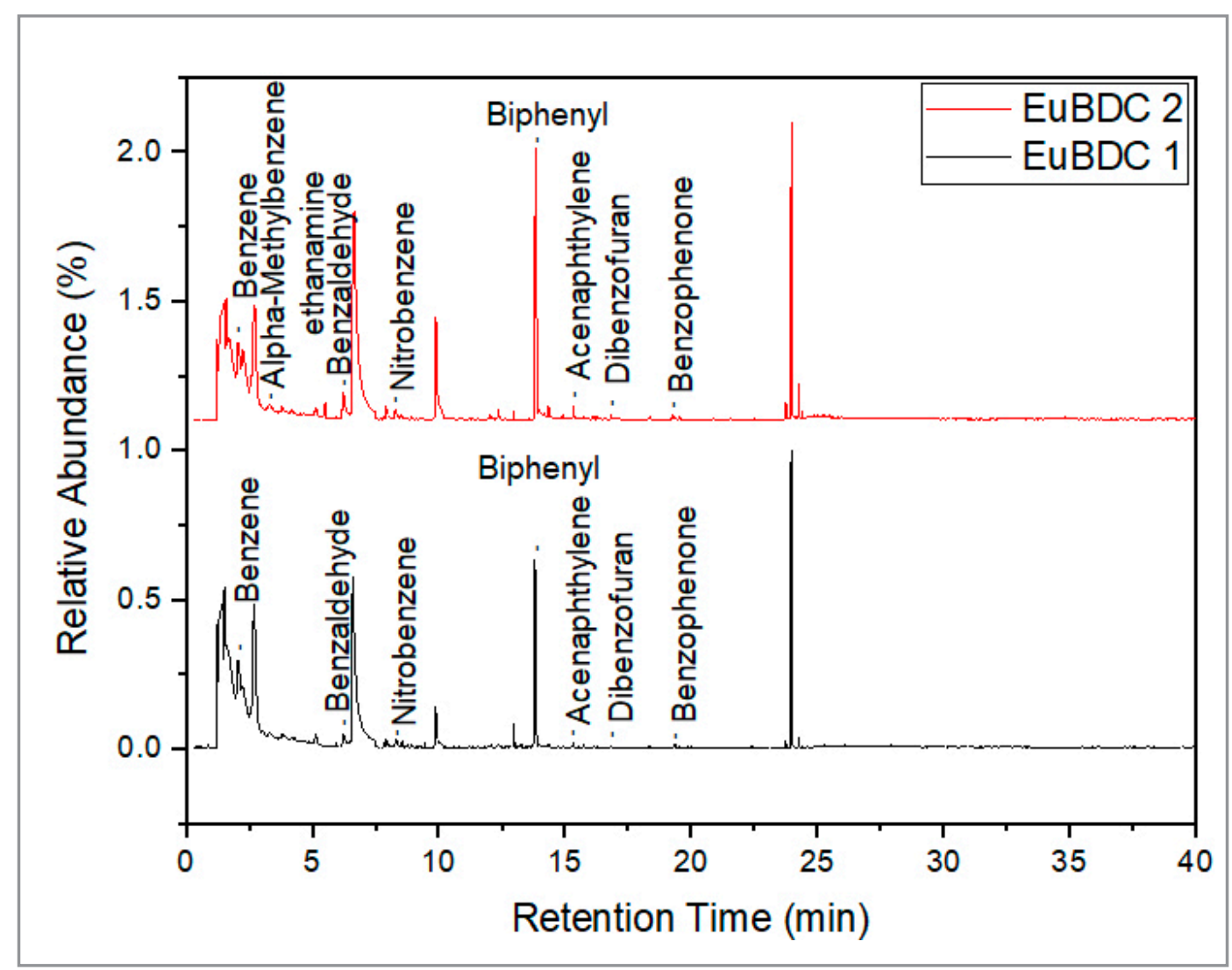

Figure 7. Chromatograms obtained from as-fired cartridge of NTA marked with EuBDC. 


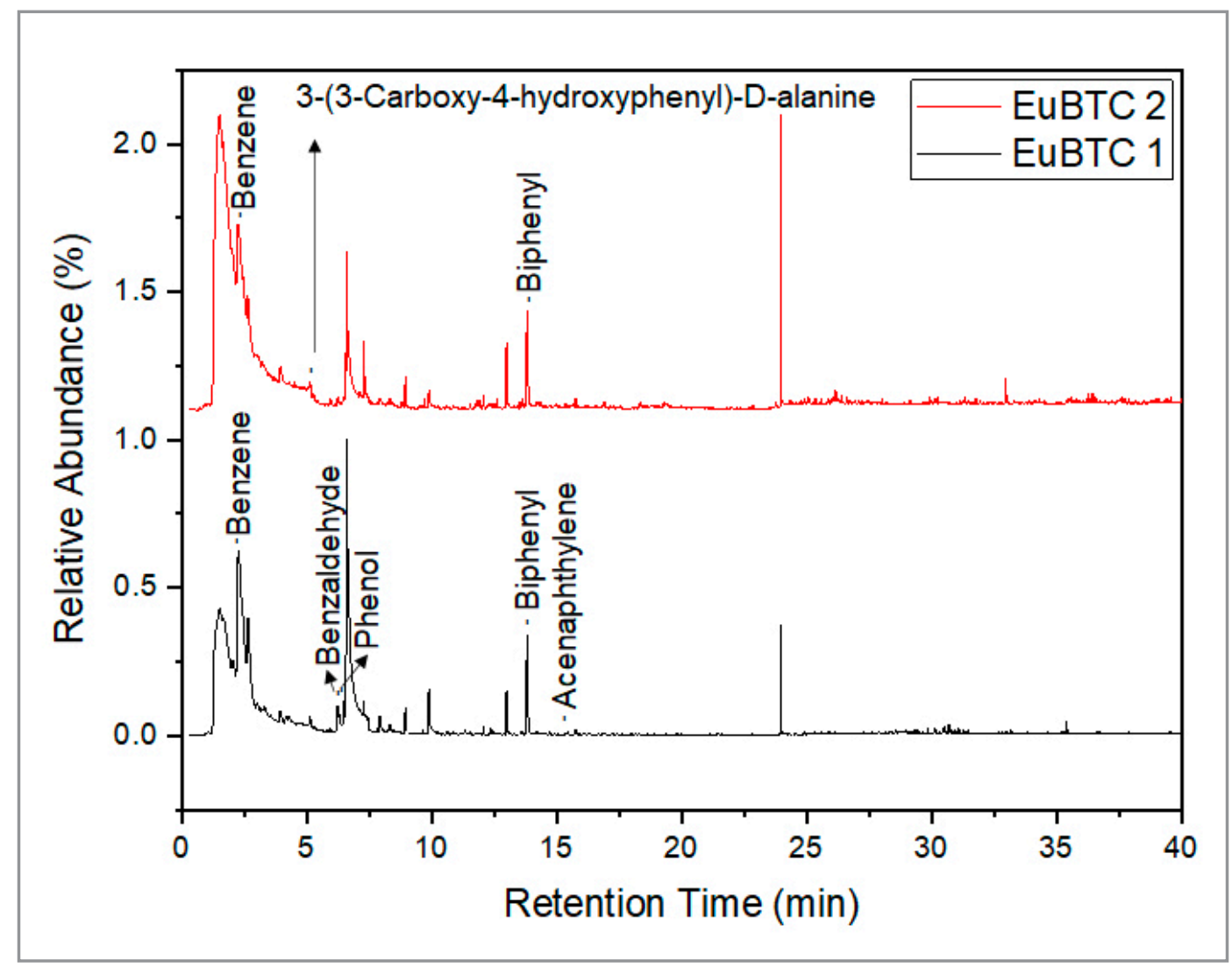

Figure 8. Chromatograms obtained from as-fired cartridge of NTA marked with EuBTC.

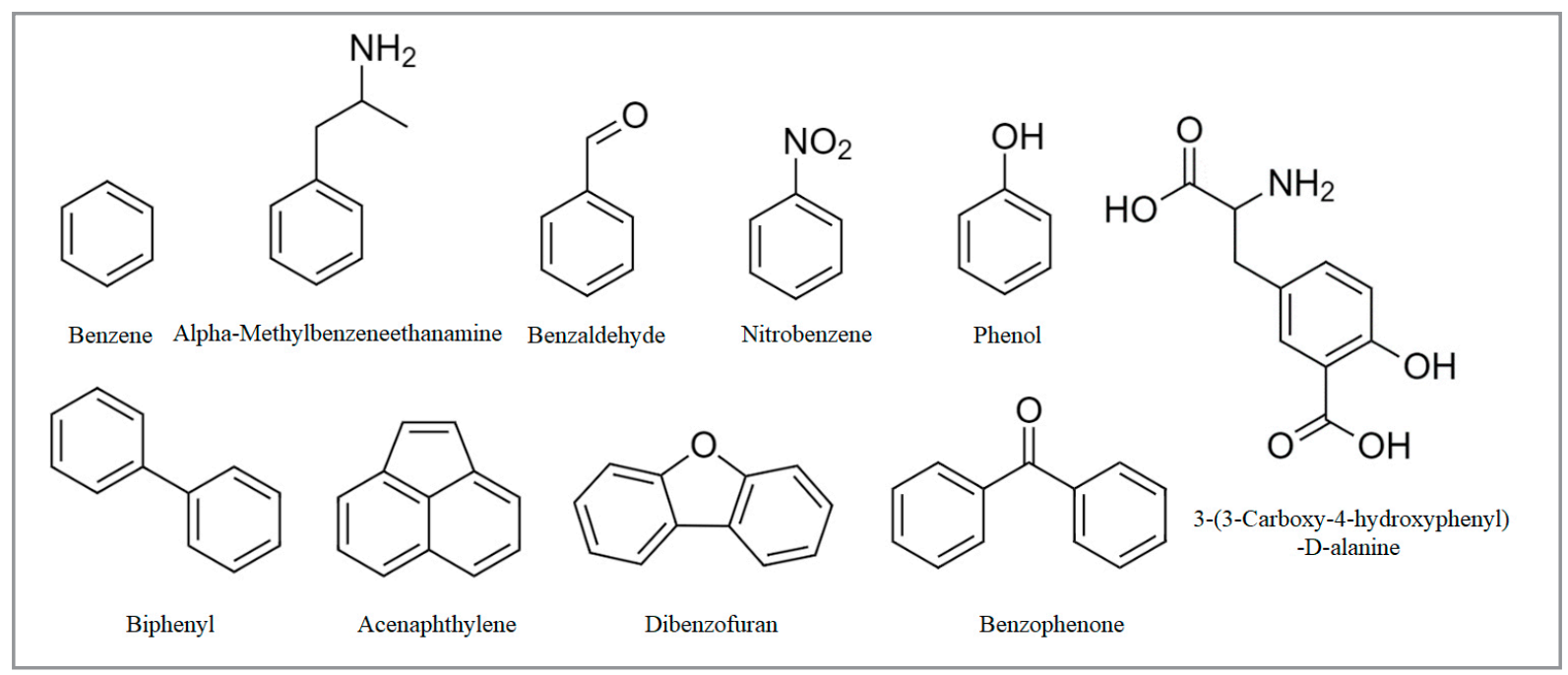

Figure 9. Structures of compounds found in GSR-NTA marked with EuBDC or EuBTC.

Among the listed compounds, pyridine and benzene are related to degradation of the markers, while the other compounds, despite not appearing in the chromatograms of pure fired NTA, may be byproducts of pure ammunition or result of a reaction between the marker and the gunpowder during the shot. For example, compounds such as phenol, biphenyl, benzaldehyde and nitrobenzene (found only in the marked samples) have already been described in the literature as byproducts of fired NTA [31,32]. Of course, they also can be due to the degradation of the markers. 
This result indicates that the structure of the LMOFs generates at least two compounds (benzene and pyrene) which can be related to the addition of the marker to the gunpowder. These compounds may pose some risk to the health of a frequent shooter who suffers chronic exposure for a prolonged period.

According to IARC [38], an acute pyridine intoxication can cause several effects on the central nervous system resulting in dizziness, headache, nausea and anorexia. In addition, inhaling the material may cause necrotic damage of the nasal epithelium. Jori et al. [39] reported a study in which workers were exposed to pyridine vapors, in a concentration of about $125 \mathrm{ppm}$, for a period of $4 \mathrm{~h}$ per day, during one to two weeks; they found the workers presented symptoms such as headache, dizziness, insomnia, nausea and anorexia.

$\mathrm{NIOSH}$ [40] considers benzene a potential human carcinogen; exposure should be reduced and controlled in the work environment. Acute intoxication, in humans, can led to nerve inflammation, central nervous system depression and cardiac sensitization. Moreover, concentrations above 3000 ppm can lead to eye irritation, nose and respiratory tract. On the other hand, chronic exposure may lead to irreversible problems in the blood-forming organs and can cause leukemia [40].

Regarding the quantity of the byproducts found, previous studies have shown that a significant portion of the LMOF remains unchanged in the firing process, this fact can be visually identified because the LGSR particles deposited on the gun, hands or at the firing site remain luminescent after the shot (Figure 10). This fact has been corroborated by previous studies [21,24] which prove that the Raman and luminescence spectral profiles also remain unchanged, showing that only a small part of the marker has been degraded.

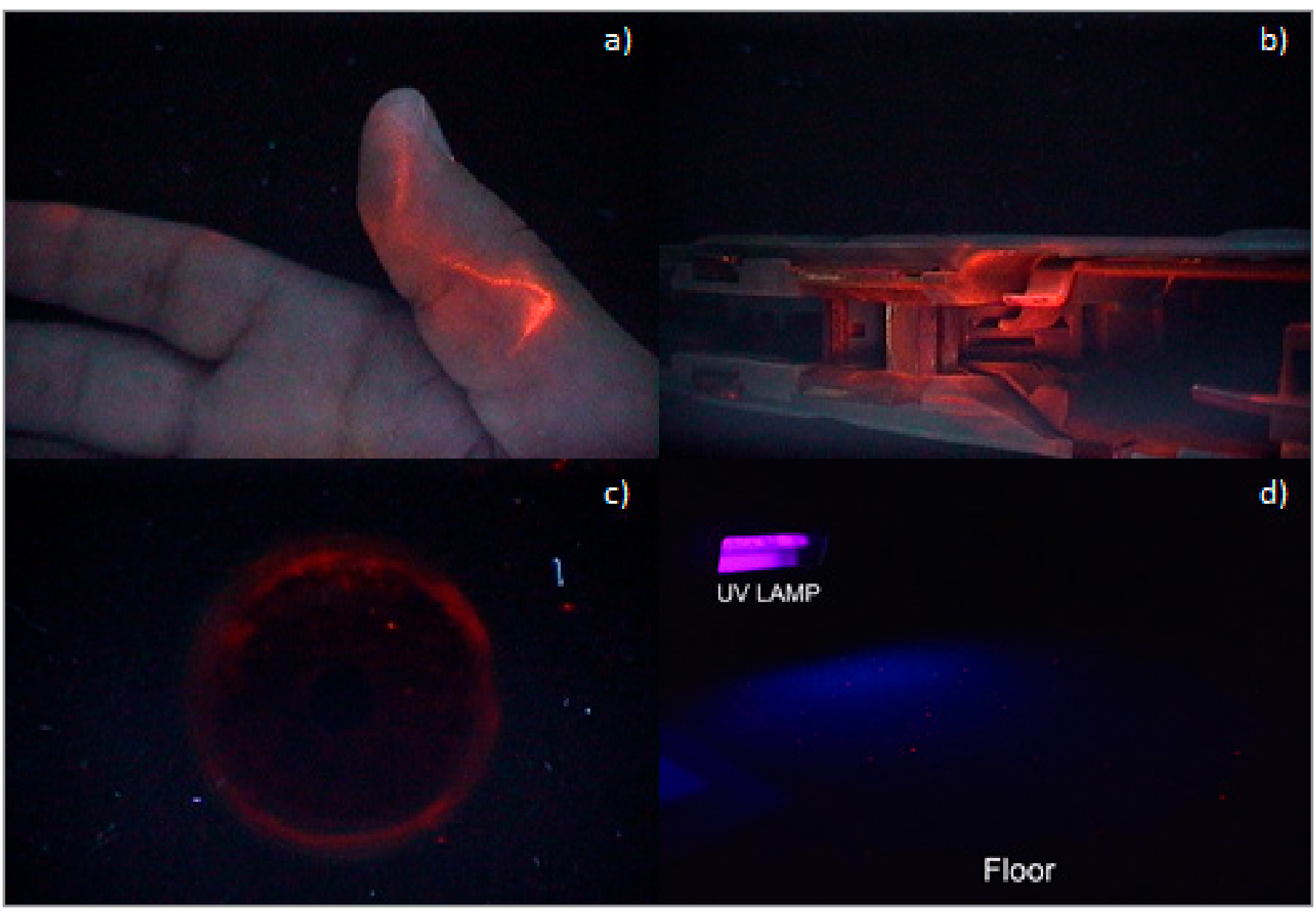

Figure 10. LGSR particles deposited on the (a) hands of the shooter, (b) gun, (c) cartridge and (d) at the shooting site irradiated with an UV lamp $(\lambda=254 \mathrm{~nm})$. 
It is possible to estimate the number of rounds that are needed to produce an acute toxic effect regarding the degradation of the markers. In each ammunition, $40 \mathrm{mg}$ of the marker was added to $400 \mathrm{mg}$ of gunpowder. Supposing that about $30 \%$ of the marker undergoes degradation (based on experience, we believe that this value is overestimated), one shot of the ammunition marked with EuBTC would produce $2.69 \mathrm{mg}$ of benzene. Considering that shot was carried out in a closed space $\left(200 \mathrm{~m}^{3}\right)$, the amount of marker needed to saturate the environment and achieve a concentration above $3000 \mathrm{ppm}$, that cause some acute toxicity effect [40], it would be necessary to fire more than 220 thousand marked ammunition with EuBTC marker. In real-life situations, this is an unrealistic scenario. Furthermore, the amount of marker added to the ammunition can be reduced up to $2 \% \mathrm{wt}$, still making it possible to visualize the LGSR produced, as described in a previous work [19]. With this change, the level of security for the use of the markers can be increased.

So, although the markers generate some toxic byproducts, the acute toxicity of NTA, as understood in our study, is not significantly altered when the LMOF is added, considering the small amount of material formed. However, the long-term exposure needs to be evaluated for both pure and marked GSR-NTA, to define a safety margin for frequent shooters.

\section{CONCLUSIONS}

The gunshot residue of an NTA was analyzed with a GC-MS analysis, using SPME as the extraction method to identify byproducts formed, and relate its toxicity to a possible toxicity of the ammunition. Many studies have been carried out on the toxicity of inorganic GSR, however, none has been carried out on the toxic effect of organic GSR. The presence of organic compounds with known toxicity can indicate a possible toxic effect of the ammunition, these compounds are known to be dangerous and still imply that, since the amount used is small, the acute effect can be disregarded, nevertheless the chronic one can be quite dangerous. In fact, for NTA ammunition studies are needed to assess the chronic toxicity of the organic part of the GSR, just as done for the inorganic one.

The toxicity effect of the NTA marked with the LMOFs ${ }_{\infty}[\mathrm{Eu}(\mathrm{DPA})(\mathrm{HDPA})],{ }_{\infty}\left[\mathrm{Eu}_{2}(\mathrm{BDC})_{3}\left(\mathrm{H}_{2} \mathrm{O}\right)_{2}\right]_{n}$ and ${ }_{\infty}[\mathrm{Eu}(\mathrm{BTC})]$ was also evaluated. The two target compounds found in fired marked cartridges were pyridine and benzene. Other compounds like phenol, biphenyl, and benzaldehyde were also identified. Although these compounds have a certain toxicity, the toxicity of pure NTA ammunition remained mainly unaltered, considering that some of those compounds could also be found in the firing of pure NTA. Furthermore, the amount of marker added to the gunpowder is too small to produce toxic effect.

\section{Conflicts of interest}

This work was supported by CNPq, CAPES PROFORENSE NEQUIFOR 3509/2014.

\section{Acknowledgements}

We thank the Brazilian Federal Police and experts Eduardo Makoto Sato, Ronei Maia Salvatori, André Lima Logrado and Elvio Dias Botelho for research collaboration. This work was supported by CNPq, CAPES PROFORENSE NEQUIFOR 3509/2014.

The English text of this paper has been revised by Sidney Pratt, Canadian, MAT (The Johns Hopkins University), RSAdip - TESL (Cambridge University).

\section{REFERENCES}

1. National Institute for Occupational Safety and Health (NIOSH). Center for Disease Control (CDC). Lead exposure and design considerations for indoor firing ranges, 1975.

2. National Institute for Occupational Safety and Health (NIOSH). Center for Disease Control (CDC). Preventing occupational exposures to lead and noise at indoor firing ranges, 2009, Volume 139.

3. Rocha, E. D.; Sarkis, J. E. S.; Carvalho, M. D. F. H.; Dos Santos, G. V.; Canesso, C. Int. J. Hyg. Environ. Health, 2014, 217 (6), pp 702-704 (https://doi.org/10.1016/j.jheh.2013.12.004). 
4. National Institute for Occupational Safety and Health (NIOSH). Reducing Exposure to Lead and Noise at Outdoor Firing Ranges, 2012.

5. National Institute for Occupational Safety and Health (NIOSH). Center for Disease Control (CDC). Reducing Exposure to Lead and Noise at Indoor Firing Ranges, 2010.

6. National Institute for Occupational Safety (NIOSH). Preventing Occupational Exposures to Lead and Noise at Indoor Firing Ranges, 2009.

7. Martiny, A.; Campos, A. P. C.; Sader, M. S.; Pinto, M. A. L. Forensic Sci. Int., 2008, 177 (1), pp e9-e17 (https://doi.org/10.1016/j.forsciint.2007.07.005).

8. Brandone, A.; De Ferrari, F.; Pelizza, P.; Signori, M. Forensic Sci. Int., 1990, 47 (3), pp 289-295 (https://doi.org/10.1016/0379-0738(90)90298-D).

9. Niewoehner, L.; Buchholz, N.; Merkel, J. The Journal of Scanning Microscopies, Proceedings of SCANNING 2005 Monterey, CA, 2005, 27, p 69.

10. Lucena, M. A. M.; De Sá, G. F.; Rodrigues, M. O.; Júnior, S. A.; Talhavini, M.; Weber, I. T. Anal. Methods, 2013, 5 (3), pp 705-709 (https://doi.org/10.1039/c2ay25535a).

11. Destefani, C.; Motta, L. C.; Vanini, G.; Souza, L. M.; Allochio Filho, J. F.; Macrino, C. J.; Silva, E. M.; Greco, S. J.; Endringer, D. C.; Romão, W. Microchem. J., 2014, 116, pp 216-224 (https://doi. org/10.1016/j.microc.2014.05.009).

12. Weber, I. T.; Geber de Melo, A. J.; Lucena, M. A. M.; Rodrigues, M. O.; Junior, S. A. Anal. Chem., 2011, 83, pp 4720-4723 (https://doi.org/10.1021/ac200680a).

13. Weber, I. T.; Terra, I. A. A.; de Melo, A. J. G.; Lucena, M. A. M.; Wanderley, K. A.; Paiva-Santos, C. O.; Antônio, S. G.; Nunes, L. A. O.; Paz, F. A. A.; de Sá, G. F.; Júnior, S. A.; Rodrigues, M. O. RSC Adv. 2012, 2 (7), pp 3083-3087 (https://doi.org/10.1039/c2ra01214f).

14. Lucena, M. A. M.; Rodrigues, M. O.; Gatto, C. C.; Talhavini, M.; Maldaner, A. O.; Alves Jr, S.; Weber, I. T. J. Lumin., 2016, 170, pp 697-700 (https://doi.org/10.1016/j.jlumin.2015.04.010).

15. Serwy, I. B.; Wanderley, K. A.; Lucena, M. A. M.; Maldaner, A. O.; Talhavini, M.; Rodrigues, M. O.; Weber, I. T. J. Lumin., 2018, 200, pp 24-29 (https://doi.org/10.1016/j.jlumin.2018.02.039).

16. Venturini Filho, E.; de Sousa Filho, P. C.; Serra, O. A.; Weber, I. T.; Lucena, M. A. M.; Luz, P. P. J. Lumin., 2018, 202, pp 89-96 (https://doi.org/10.1016/j.jlumin.2018.05.012).

17. Júnior, J. C. A.; dos Santos, G. L.; Colaço, M. V.; Barroso, R. C.; Ferreira, F. F.; dos Santos, M. V.; de Campos, N. R.; Marinho, M. V.; Jesus, L. T.; Freire, R. O.; Marques, L. F. J. Phys. Chem. C, 2020, 124 (18), pp 9996-10006 (https://doi.org/10.1021/acs.jpcc.0c01374).

18. Silva, M. A.; de Campos, N. R.; Ferreira, L. A.; Flores, L. S.; Júnior, J. C. A.; dos Santos, G. L.; Corrêa, C. C.; dos Santos, T. C.; Ronconi, C. M.; Colaço, M. V.; et al. Inorganica Chim. Acta, 2019, 495, 118967 (https://doi.org/10.1016/j.ica.2019.118967).

19. Weber, I. T.; Melo, A. J. G.; Lucena, M. A. M.; Consoli, E. F.; Rodrigues, M. O.; de Sá, G. F.; Maldaner, A. O.; Talhavini, M.; Alves, S. J. Forensic Sci. Int., 2014, 244, pp 276-284 (https://doi.org/10.1016/j. forsciint.2014.09.001).

20. Arouca, A. M.; Lucena, M. A. M.; Rossiter, R. J.; Talhavini, M.; Weber, I. T. Forensic Sci. Int., 2017, 281, pp 161-170 (https://doi.org/10.1016/j.forsciint.2017.09.022).

21. Lucena, M. A. M.; Ordoñez, C.; Weber, I. T.; Torre, M.; García-Ruiz, C.; López-López, M. Forensic Sci. Int., 2017, 280, pp 95-102 (https://doi.org/10.1016/j.forsciint.2017.09.013).

22. Arouca, A. M.; Lucena, M. A. M.; Rossiter, R. J.; Talhavini, M.; Weber, I. T. J. Forensic Sci., 2020, 65 (1), pp 67-72 (https://doi.org/10.1111/1556-4029.14143).

23. Lucena, M. A. M.; Arouca, A. M.; Talhavini, M.; Alves-Júnior, S.; Weber, I. T. Microchem. J., 2019, 145, pp 539-546 (https://doi.org/10.1016/j.microc.2018.09.013).

24. Carneiro, C. R.; Silva, C. S.; De Carvalho, M. A.; Pimentel, M. F.; Talhavini, M.; Weber, I. T. Anal. Chem., 2019, 91 (19), pp 12444-12452 (https://doi.org/10.1021/acs.analchem.9b03079).

25. Lucena, M. A. M.; Oliveira, M. F. L.; Arouca, A. M.; Talhavini, M.; Ferreira, E. A.; Alves, S.; Veiga-Souza, F. H.; Weber, I. T. ACS Appl. Mater. Interfaces, 2017, 9 (5), pp 4684-4691 (https://doi.org/10.1021/ acsami.6b13474). 
26. Talhari, A. L. R.; Lucena, M. A. M.; Mauricio, F. G. M.; Oliveira, M. F. L.; Veiga-Souza, F. H.; Alves Junior, S.; Weber, I. T. ACS Appl. Bio Mater., 2020, 3 (5), pp 3049-3056 (https://doi.org/10.1021/ acsabm.0c00107).

27. Fernandes, A.; Jaud, J.; Dexpert-Ghys, J.; Brouca-Cabarrecq, C. Polyhedron, 2001, 20 (18), pp 2385-2391 (https://doi.org/10.1016/S0277-5387(01)00841-5).

28. Qu, Y.; Ke, Y.; Lu, S.; Fan, R.; Pan, G.; Li, J. J. Mol. Struct., 2005, 734 (1-3), pp 7-13 (https://doi. org/10.1016/j.molstruc.2004.03.035).

29. Serre, C.; Millange, F.; Thouvenot, C.; Gardant, N.; Pelle, F.; Férey, G. J. Mater. Chem., 2004, 14 (10), pp 1540-1543 (https://doi.org/10.1039/B312425H).

30. Taudte, R. V.; Beavis, A.; Blanes, L.; Cole, N.; Doble, P.; Roux, C. Biomed Res. Int., 2014, 2014 (https:// doi.org/10.1155/2014/965403).

31. Weyermann, C.; Belaud, V.; Riva, F.; Romolo, F. S.; Forensic Sci. Int., 2009, 186 (1-3), pp 29-35 (https://doi.org/10.1016/j.forsciint.2009.01.005).

32. Goudsmits, E.; Sharples, G. P.; Birkett, J. W. TrAC Trends Anal. Chem., 2015, 74, pp $46-57$ (https:// doi.org/10.1016/j.trac.2015.05.010).

33. Agency for Toxic Substances and Diseasw Registry (ATSDR). Toxicological Profile for Naphthalene, 1-Methylnaphthalene and 2-Methylnaphthalen. Available at: http://www.atsdr.cdc.gov/toxprofiles/tp67. pdf [Accessed 08 October 2016].

34. International Agency for Research on Cancer (IARC). IARC Monographs on the Evalution of Carcinogenic Risks to Humans: Some Traditional Herbal Medicines, Some Mycotoxins, Naphthalene and Styrene, 2002, Volume 82.

35. Shopp, G. M.; White, K. L.; Holsapple, M. P.; Barnes, D. W.; Duke, S. S.; Anderson, A. C.; Condie, L. W.; Hayes, J. R.; Borzelleca, J. F. Fundam. Appl. Toxicol., 1984, 4, pp 406-419 (https://doi. org/10.1016/0272-0590(84)90198-2).

36. National Library of Medicine (NLM). Hazardous Substances Data Bank (HSDB), 2003.

37. Tanii, H.; Hashimoto, K. Arch. Toxicol., 1984, 55, pp 47-54.

38. International Agency for Research on Cancer (IARC). IARC Monographs on the Evaluation of Carcinogenic Risks to Humans, 2000, Volume 77.

39. Jori, A.; Calamari, D.; Cattabeni, F.; Di Domenico, A.; Galli, C. L.; Galli, E.; Silano, V. Ecotoxicol. Environ. Saf., 1983, 7 (3), pp 251-275 (https://doi.org/10.1016/0147-6513(83)90071-4).

40. Nacional Institute for Occupational Safety and Health (NIOSH). Center for Disease Control (CDC). Occupational Health and Safety Guideline for Benzene, 1988. 


\section{Supplementary Material}

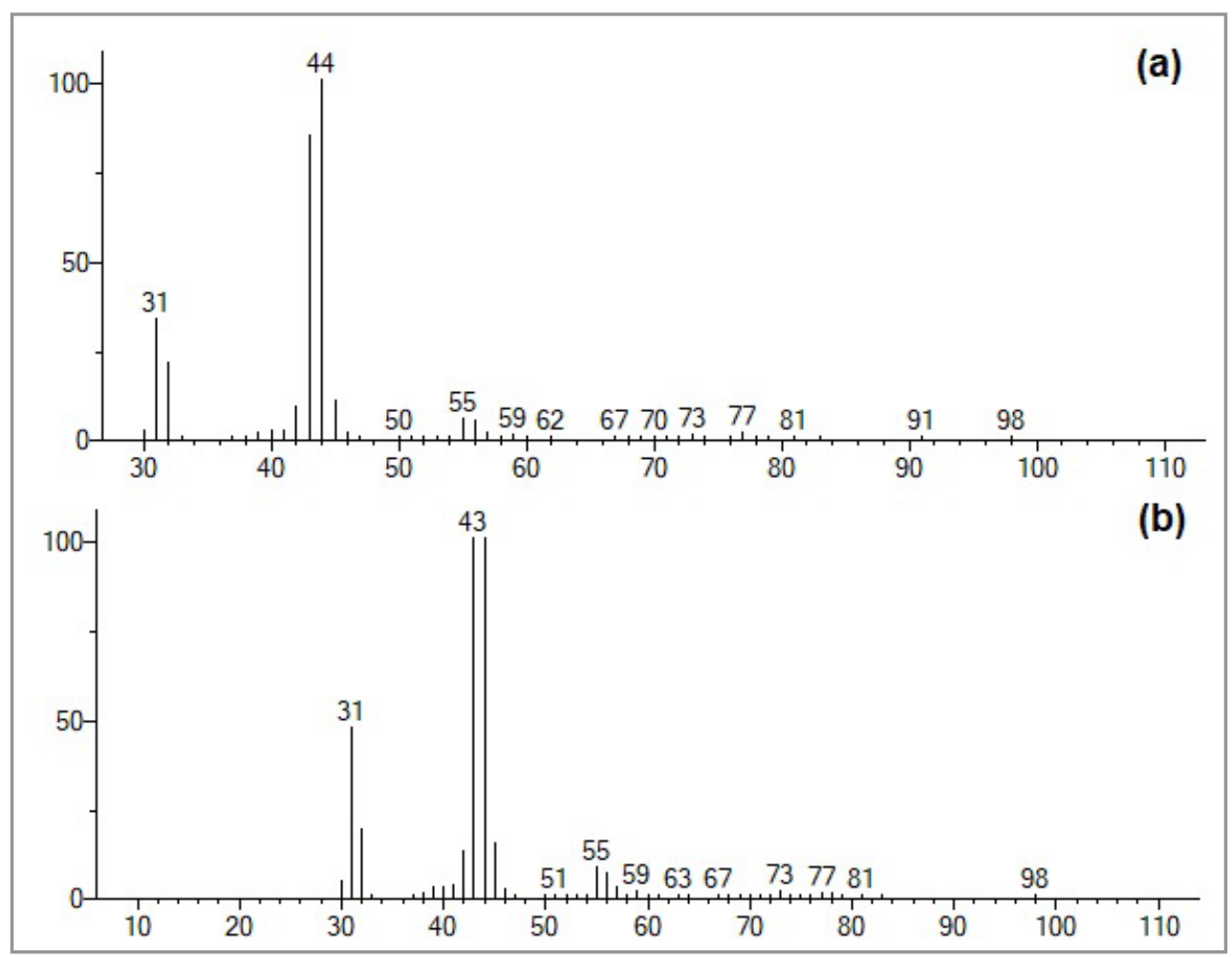

GC-MS spectra of Glycidol (retention time 2.720-2.727 min in samples (a) NTA 1 and (b) NTA 2.

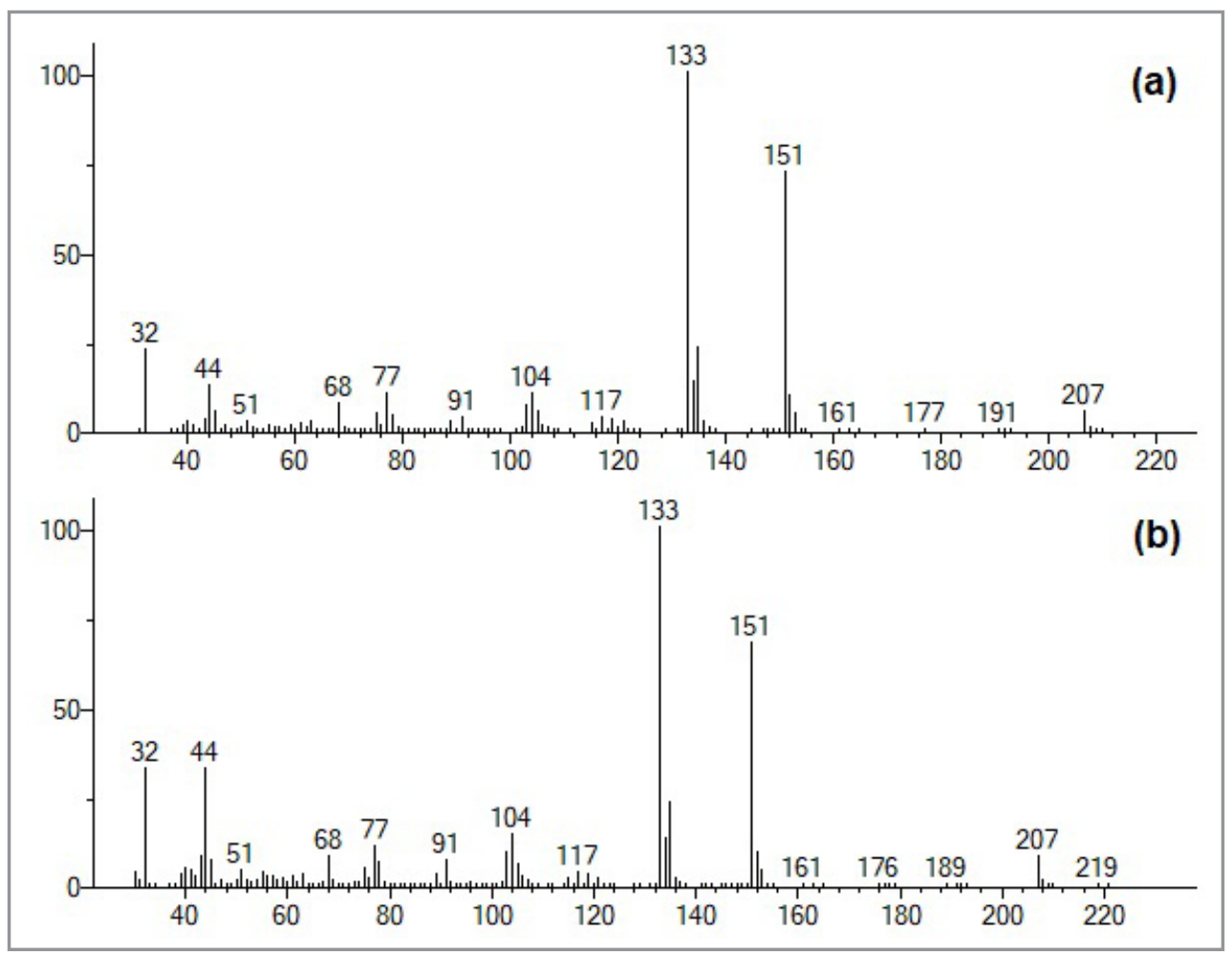

GC-MS spectra of oxime-methoxy-phenyl (retention time $5.191 \mathrm{~min}$ ) in samples (a) NTA 1 and (b) NTA 2. 


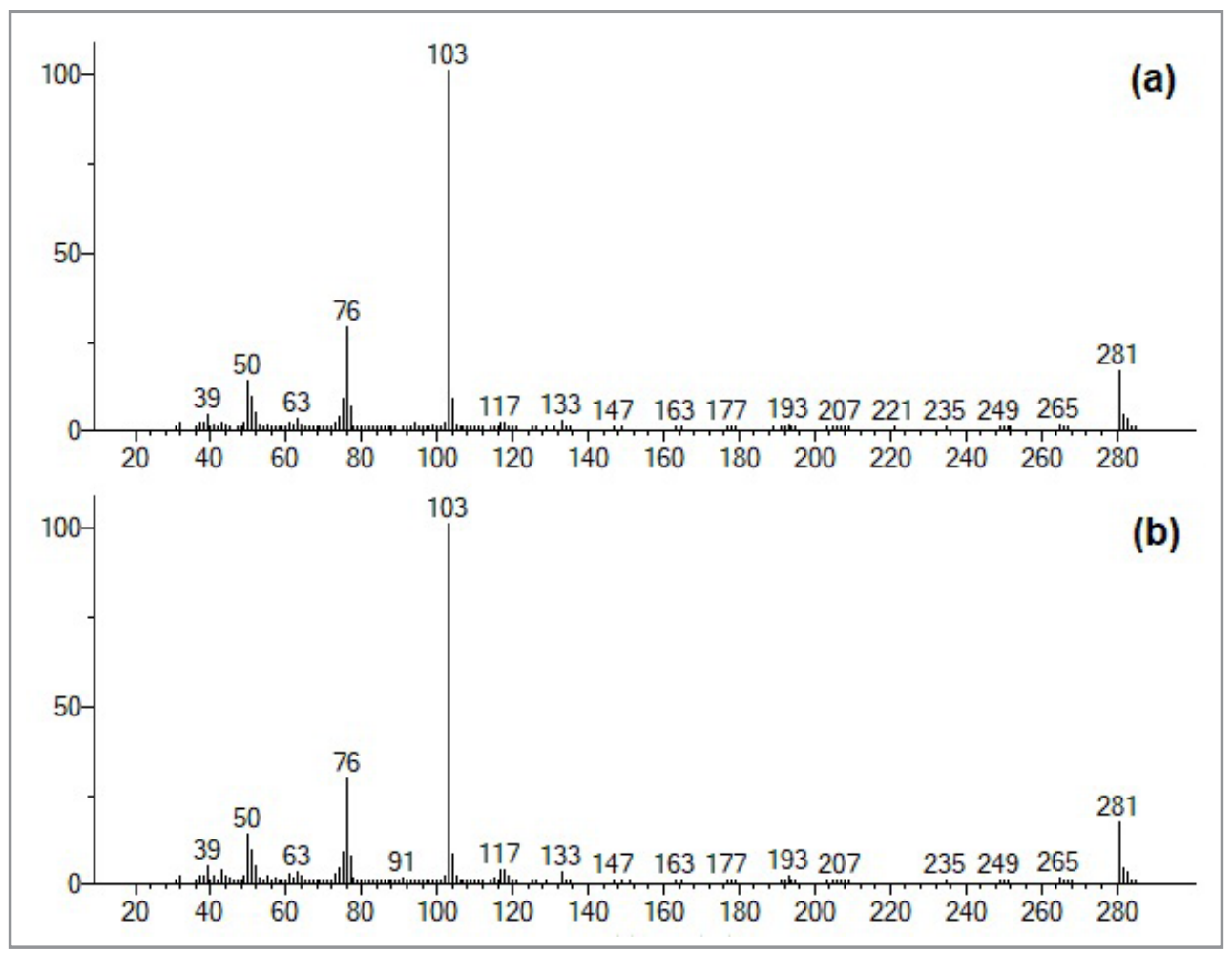

GC-MS spectra of benzonitrile (retention time $6.668 \mathrm{~min}$ ) in samples (a) NTA 1 and (b) NTA 2.

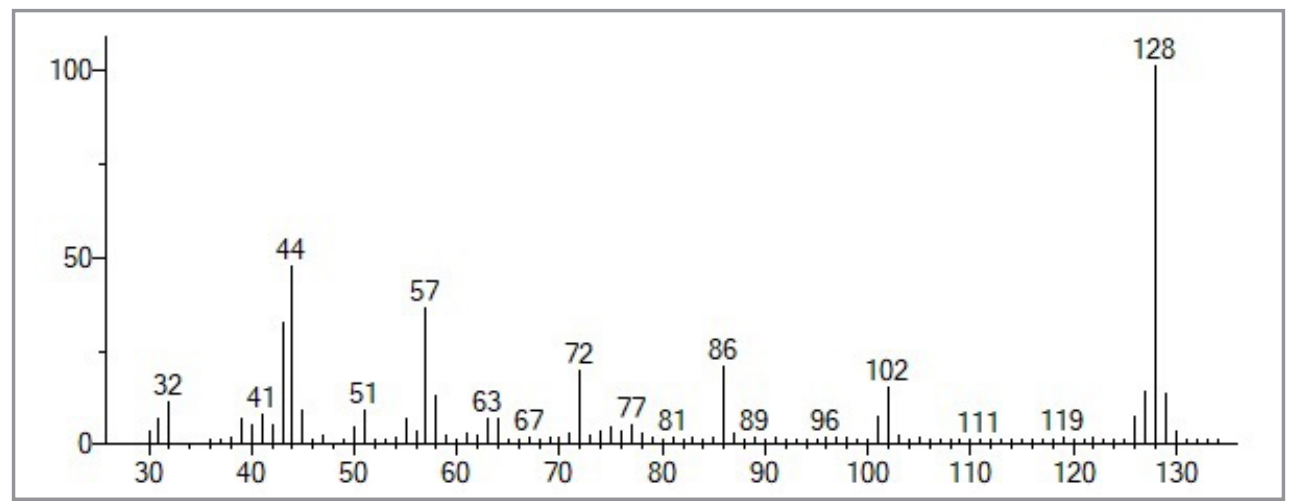

GC-MS spectra of naphthalene (retention time $9.992 \mathrm{~min}$ ) in sample NTA 1.

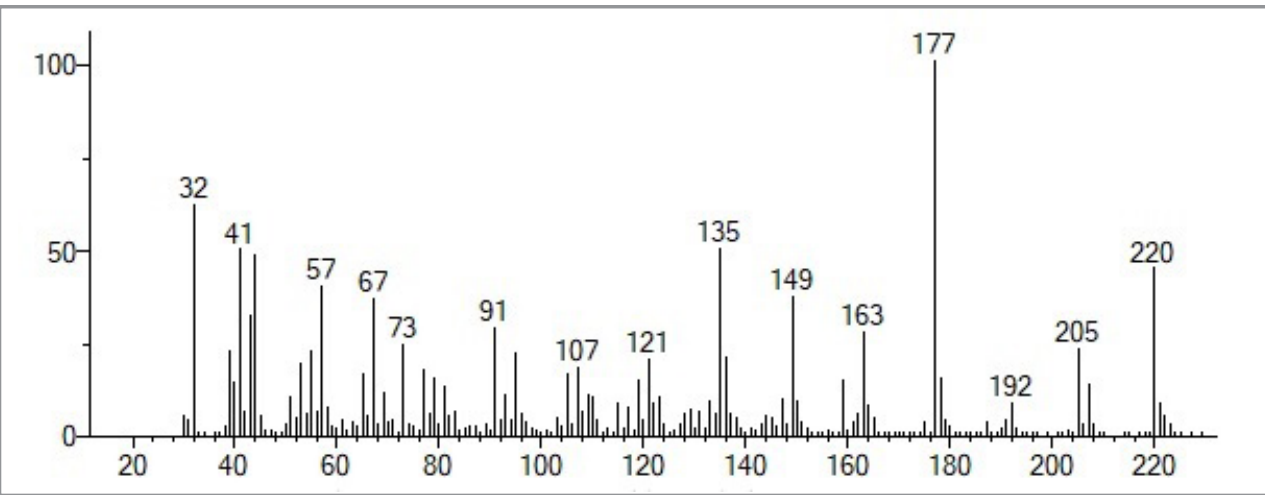

GC-MS spectra of 2,6-di-tert-butylbenzoquinone (retention time $15.703 \mathrm{~min}$ ) in sample NTA 2. 


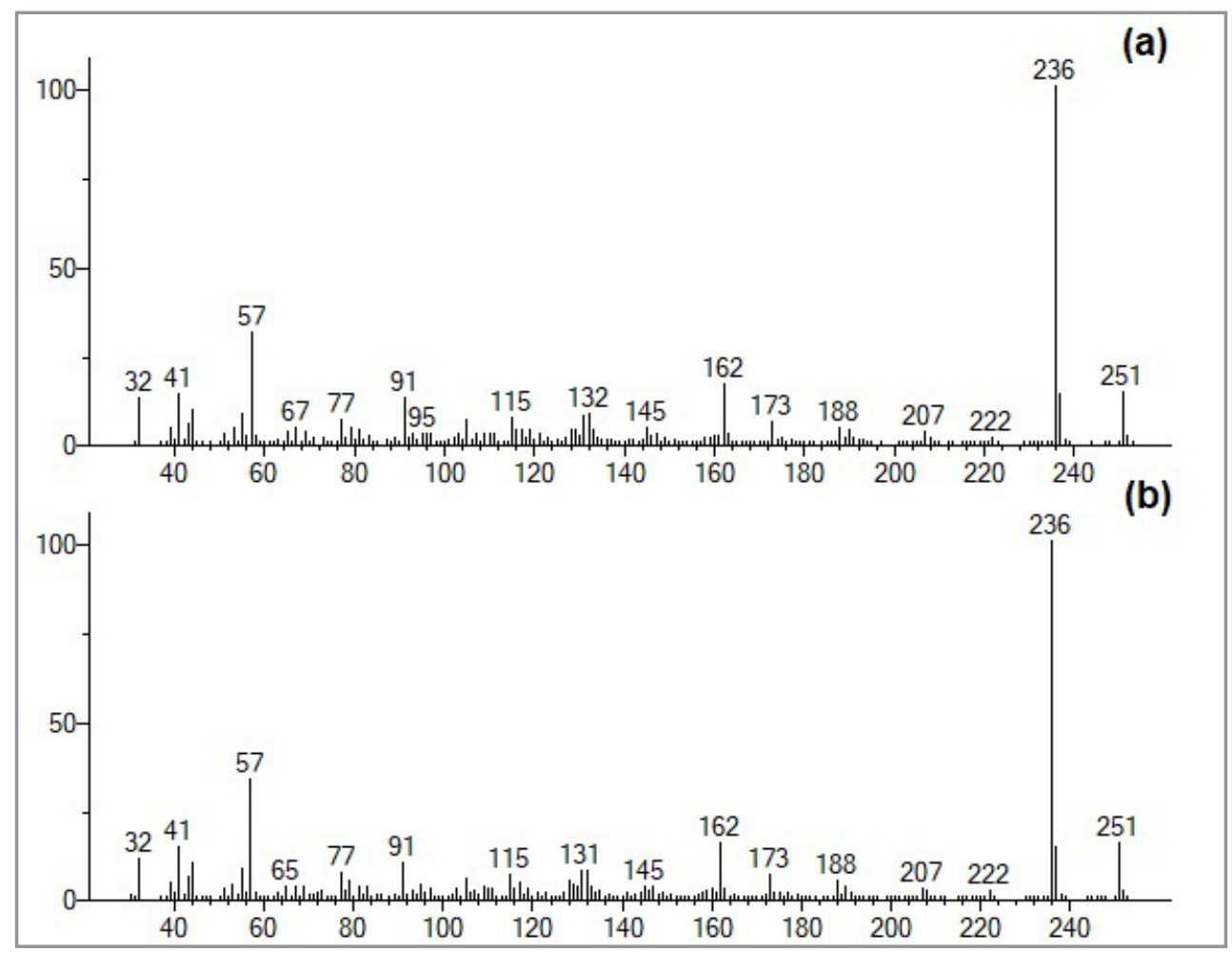

GC-MS spectra of 2,4-ditert-butyl-6-nitrophenol (retention time 20.058-20.445 min) in samples (a) NTA 1 and (b) NTA 2.

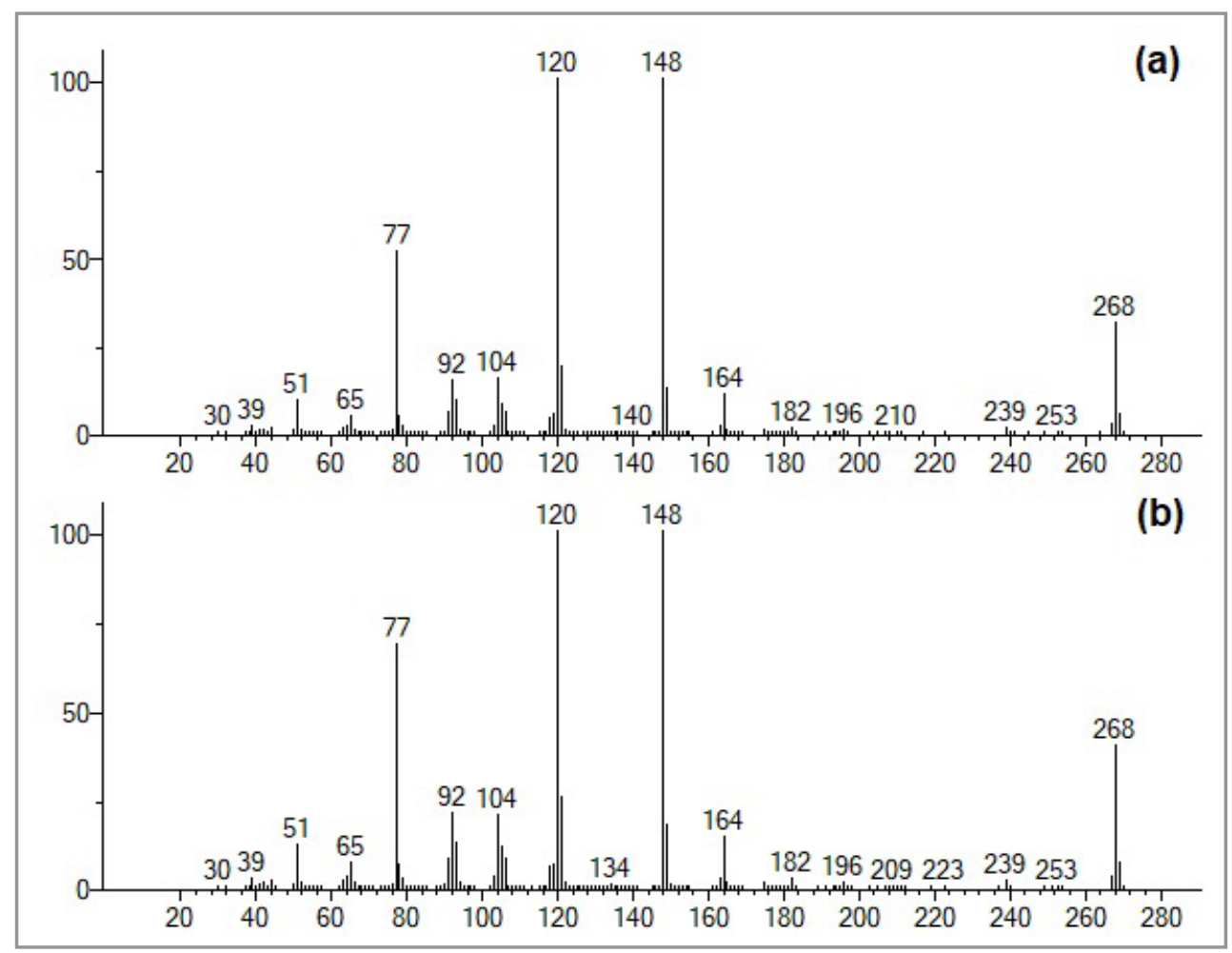

GC-MS spectra of N,N'-diethyl-N,N'-diphenylurea (retention time 24.059-24.452 min) in samples (a) NTA 1 and (b) NTA 2. 


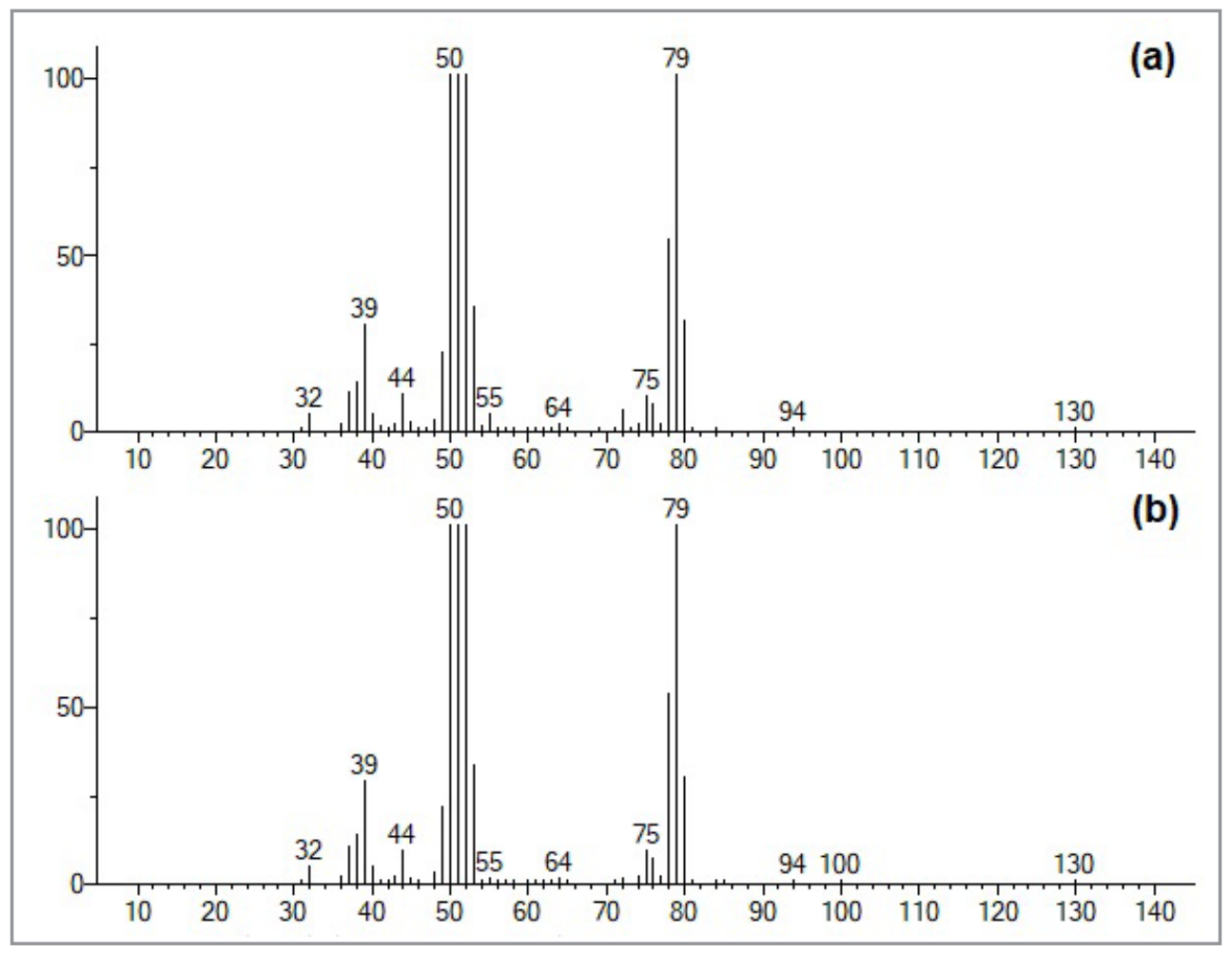

GC-MS spectra of pyridine (retention time 3.002-3.015 min) in samples (a) DPA 1 and (b) DPA 2.

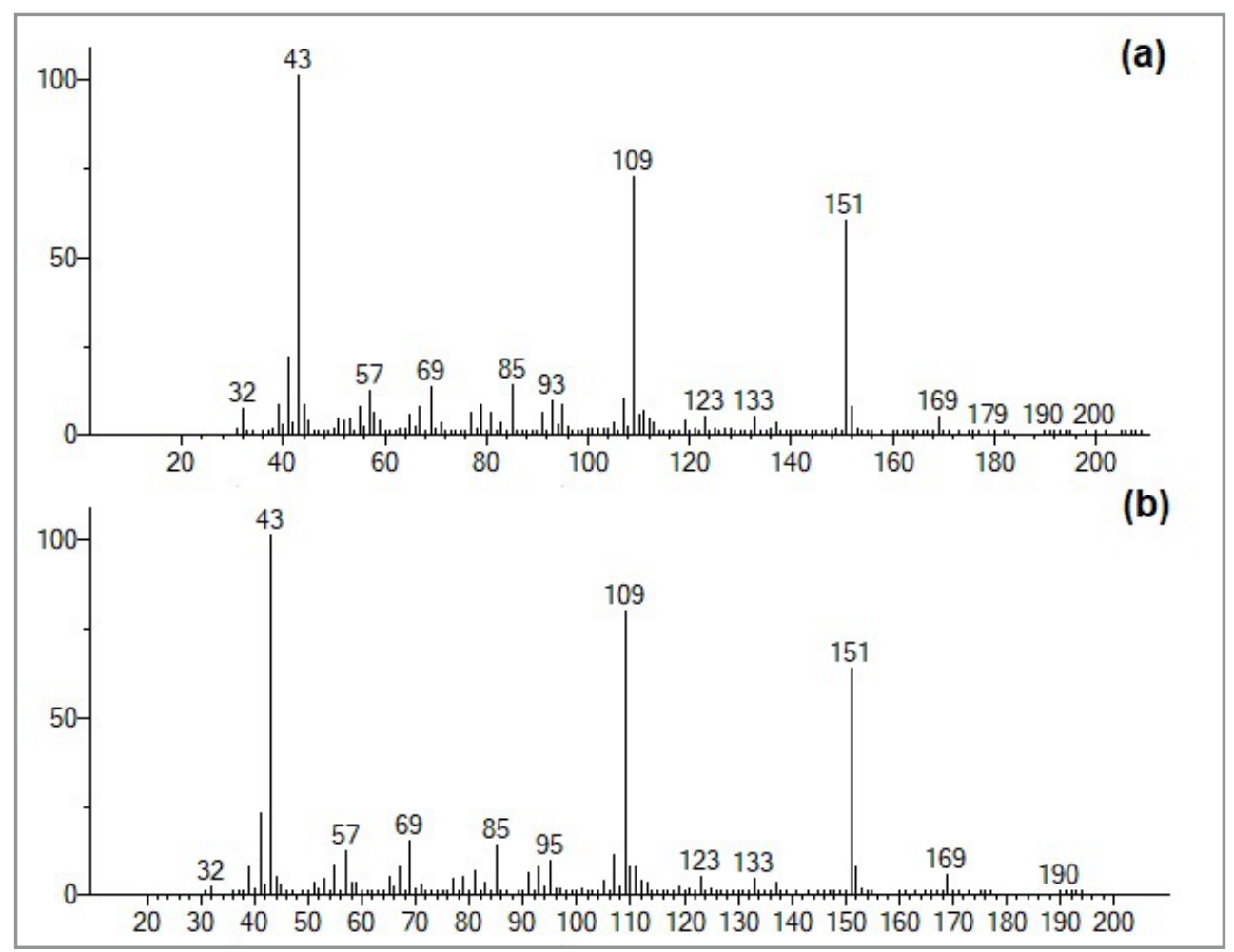

GC-MS spectra of 2,4,7,9-tetramethyl-5-decyne-4,7-diol (retention time 14.357$14.362 \mathrm{~min}$ ) in samples (a) DPA 1 and (b) DPA 2. 


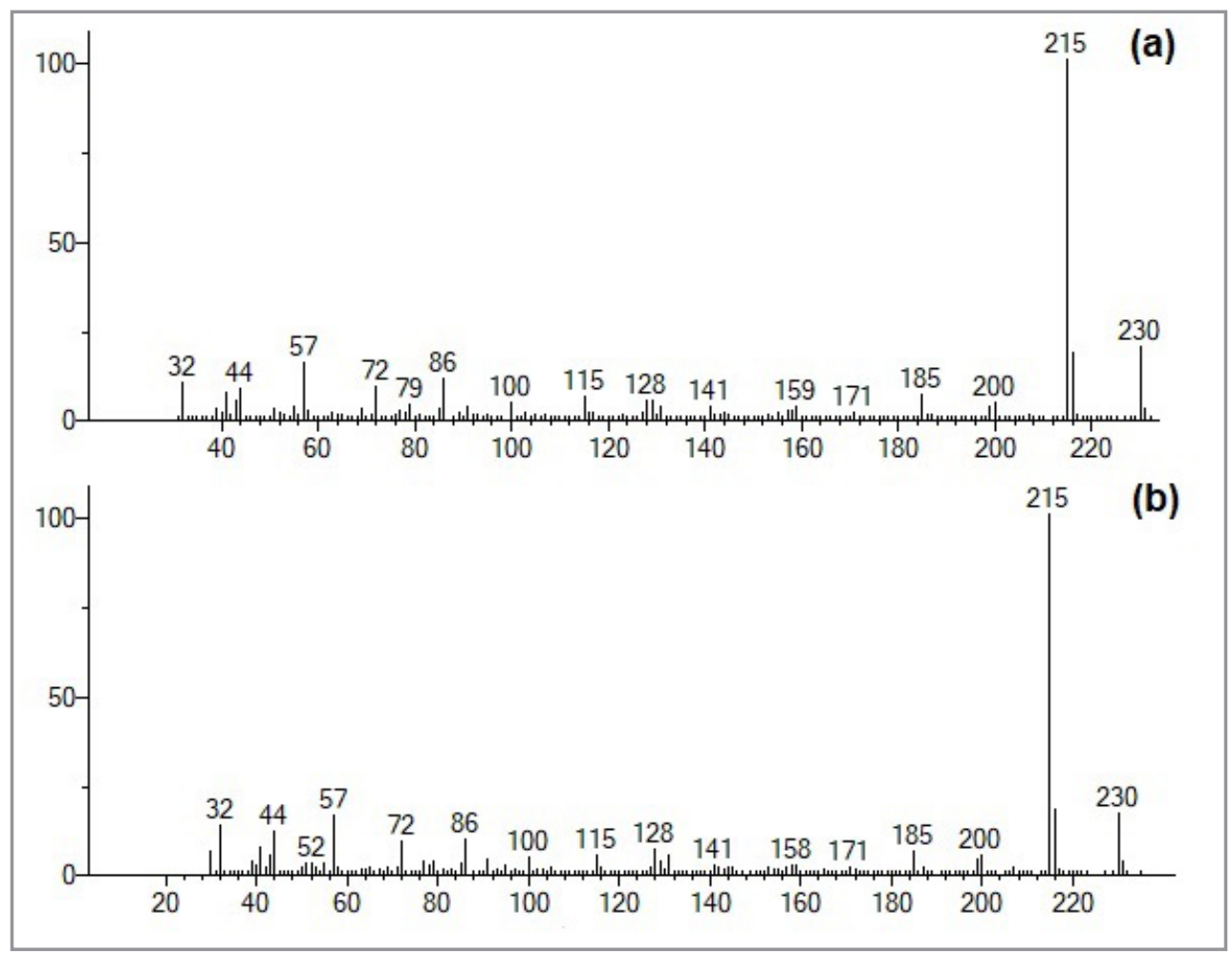

GC-MS spectra of 6-tert-butyl-4-ethyl-1,1-dimethylindan (retention time 19.155$19.156 \mathrm{~min}$ ) in samples (a) DPA 1 and (b) DPA 2.

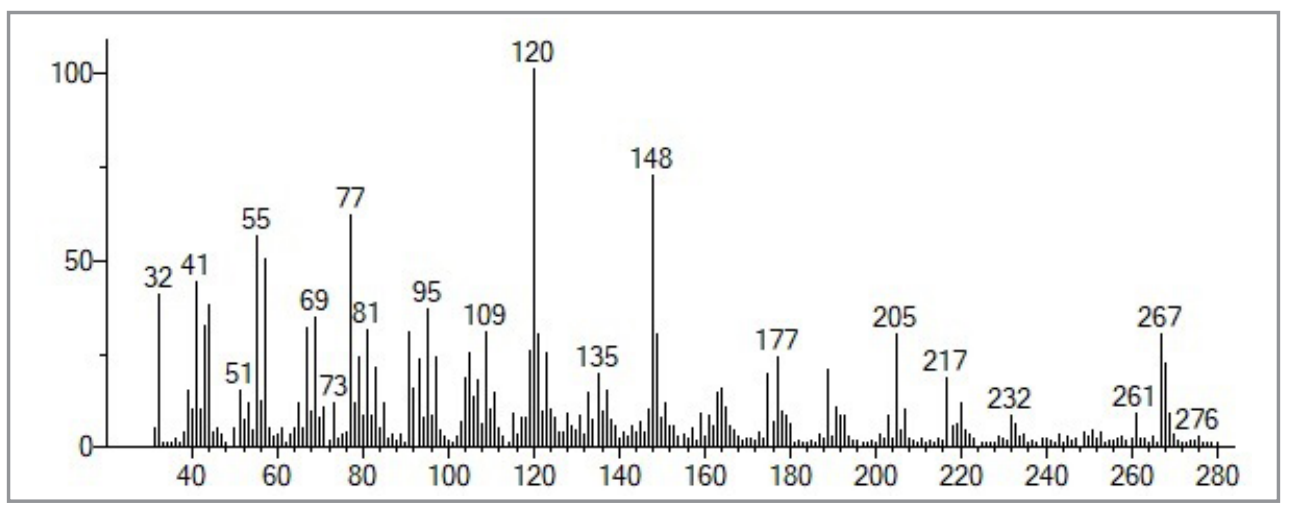

GC-MS spectra of 7,9-di-tert-butyl-1-oxaspiro(4,5)deca-6,9-diene-2,8-dione (retention time 24.104 $\mathrm{min}$ ) in sample DPA 1. 


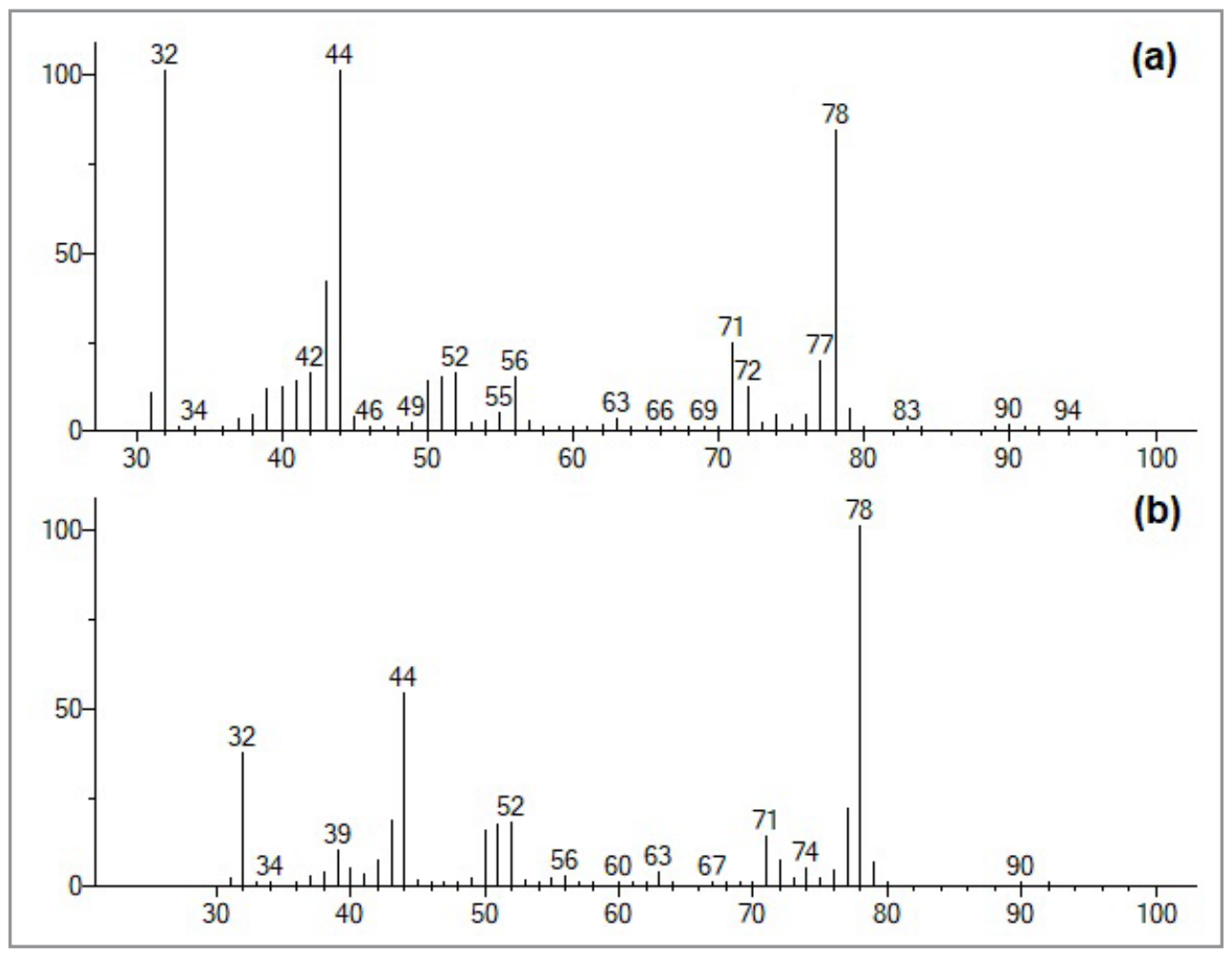

GC-MS spectra of benzene (retention time 2.231-2.248 min) in samples (a) BDC 1 and (b) BDC 2.

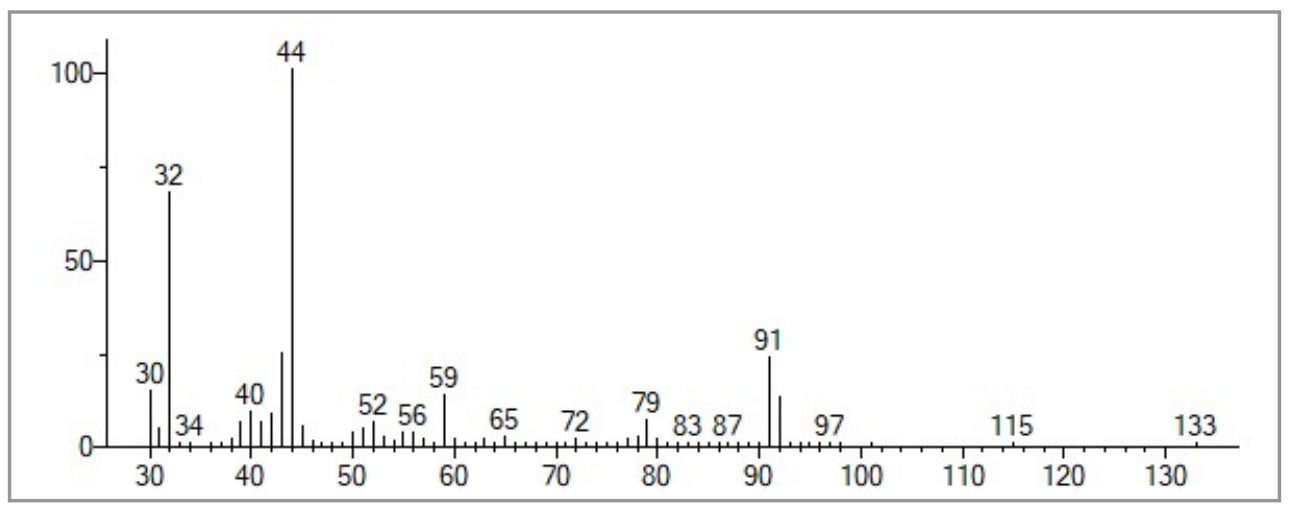

GC-MS spectra of alfa-methylbenzeneethanamine (retention time $3.298 \mathrm{~min}$ ) in sample BDC 2. 


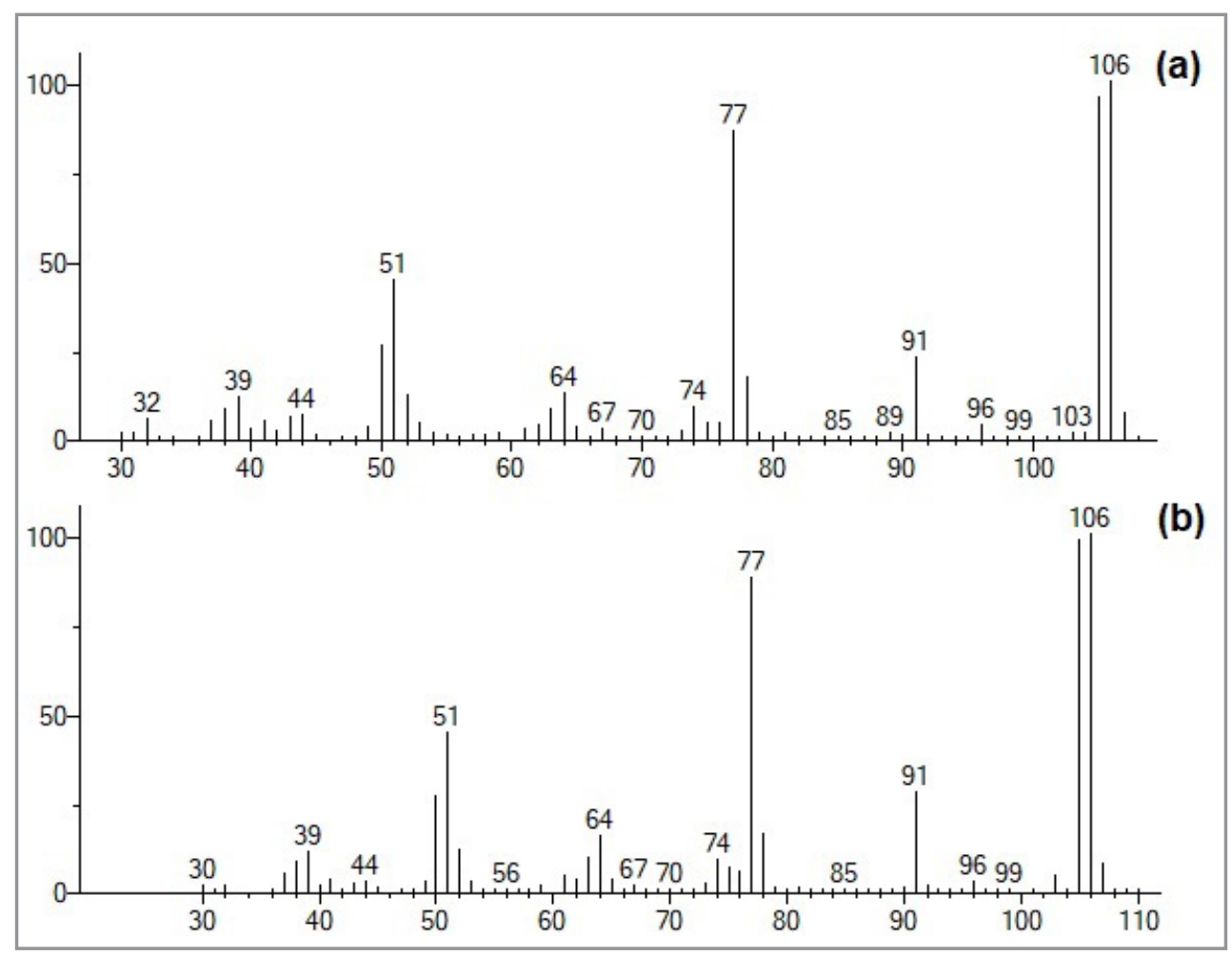

GC-MS spectra of benzaldehyde (retention time $6.235 \mathrm{~min}$ ) in samples (a) BDC 1 and (b) BDC 2.

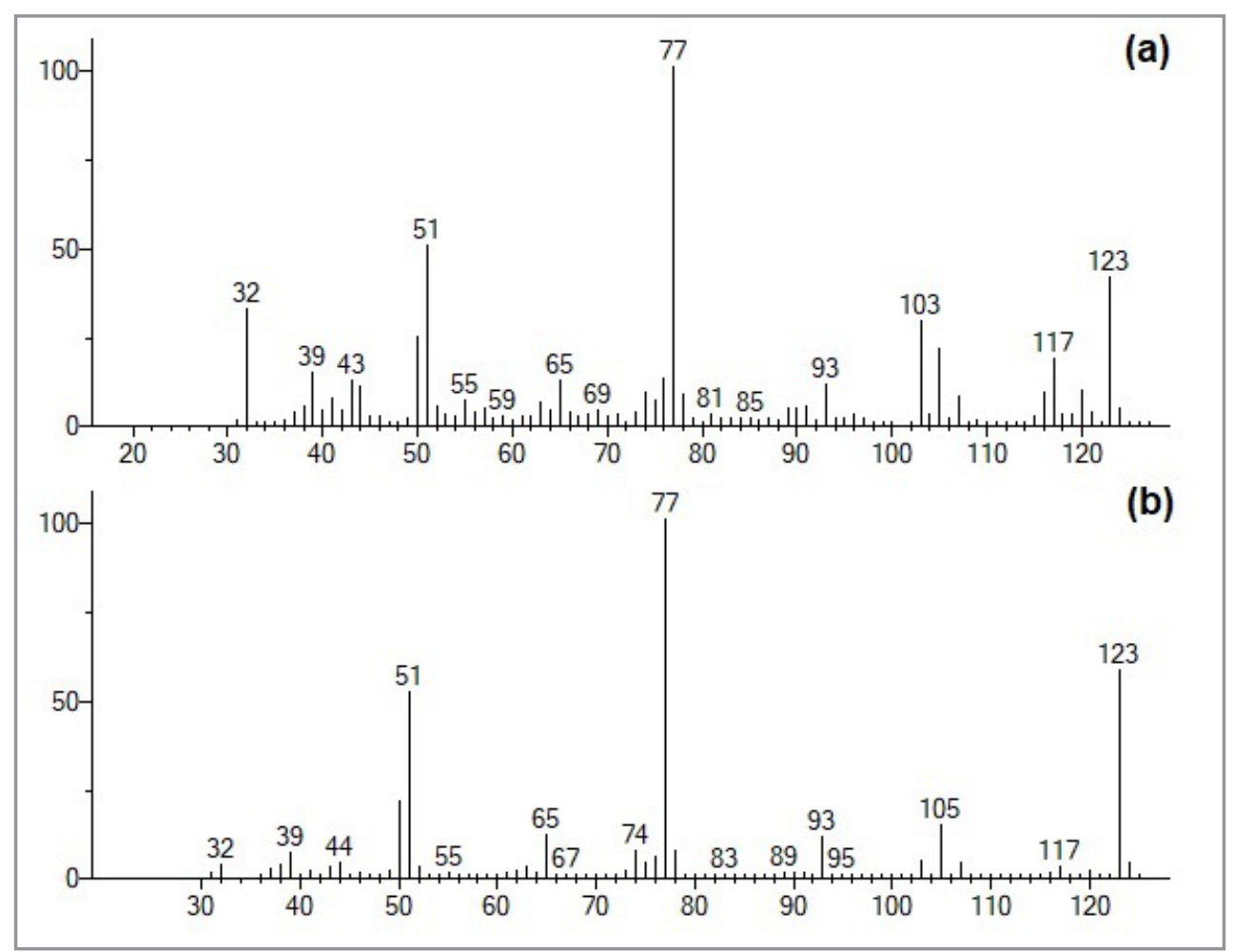

GC-MS spectra of nitrobenzene (retention time 8.244-8.249 min) in samples (a) BDC 1 and (b) BDC 2. 


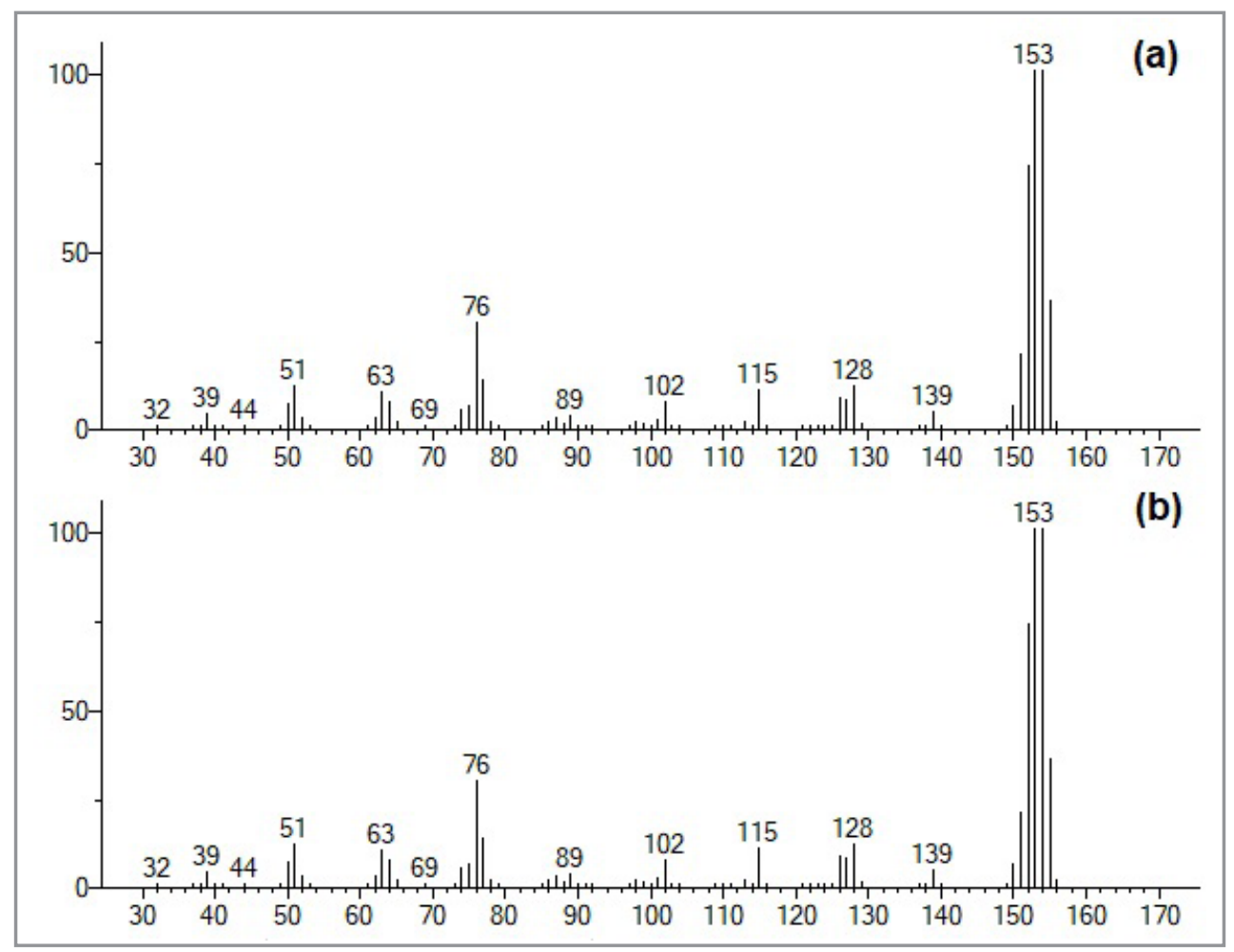

GC-MS spectra of biphenyl (retention time 13.820-13.872 min) in samples (a) BDC 1 and (b) BDC 2.

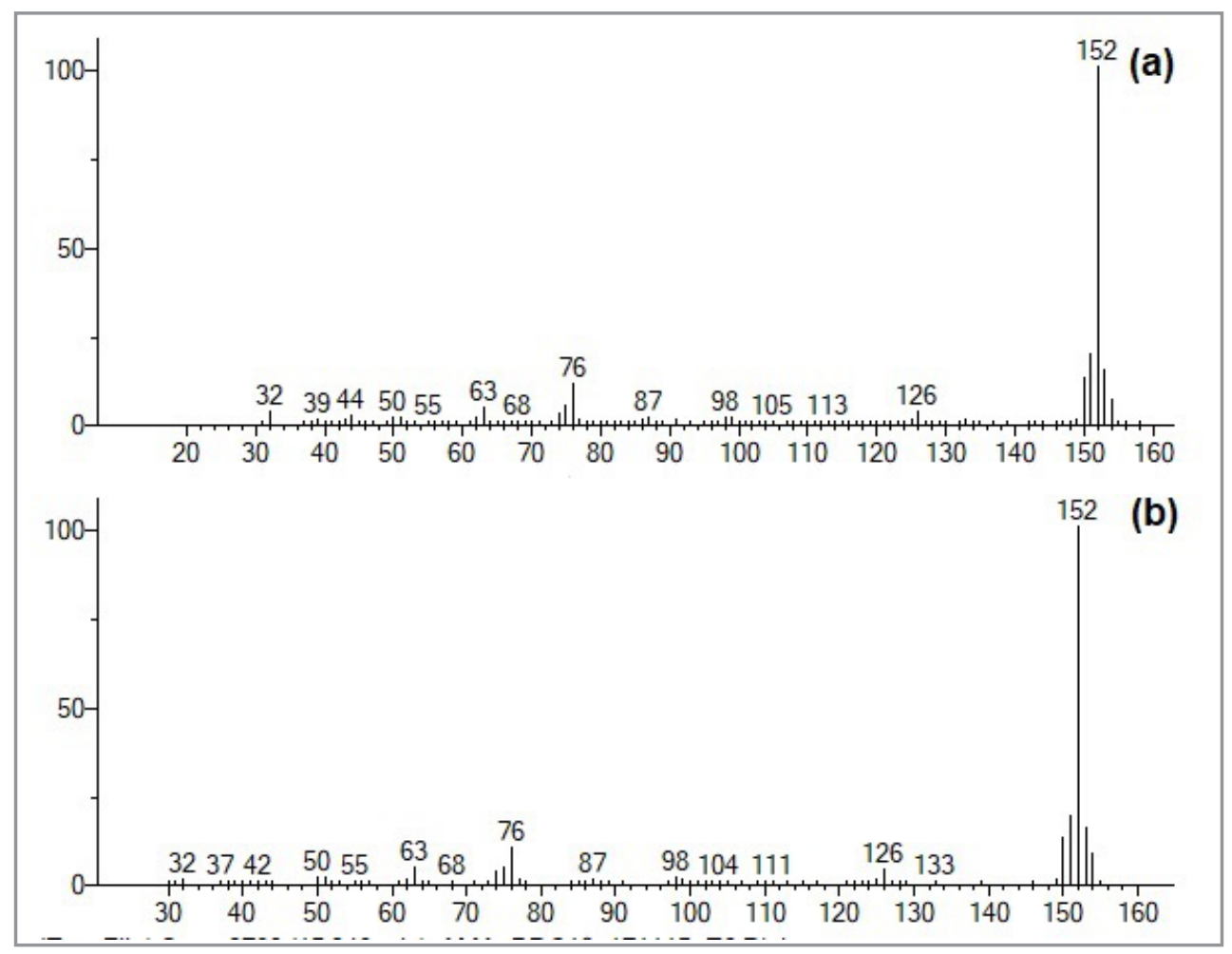

GC-MS spectra of acenaphthylene (retention time 15.346-15.347 min) in samples (a) BDC 1 and (b) BDC 2. 


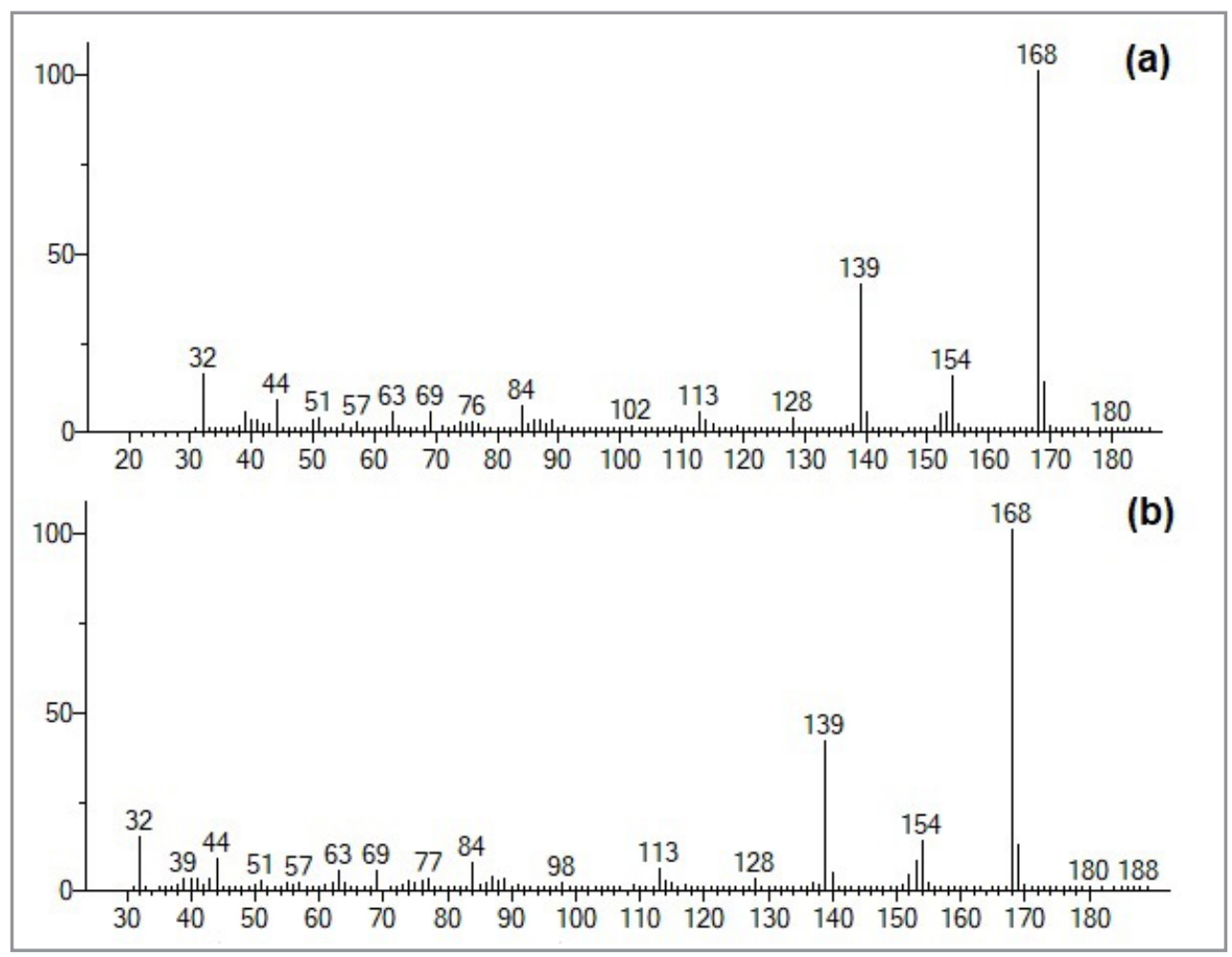

GC-MS spectra of dibenzofuran (retention time 16.833-16.834 min) in samples (a) BDC 1 and (b) BDC 2.

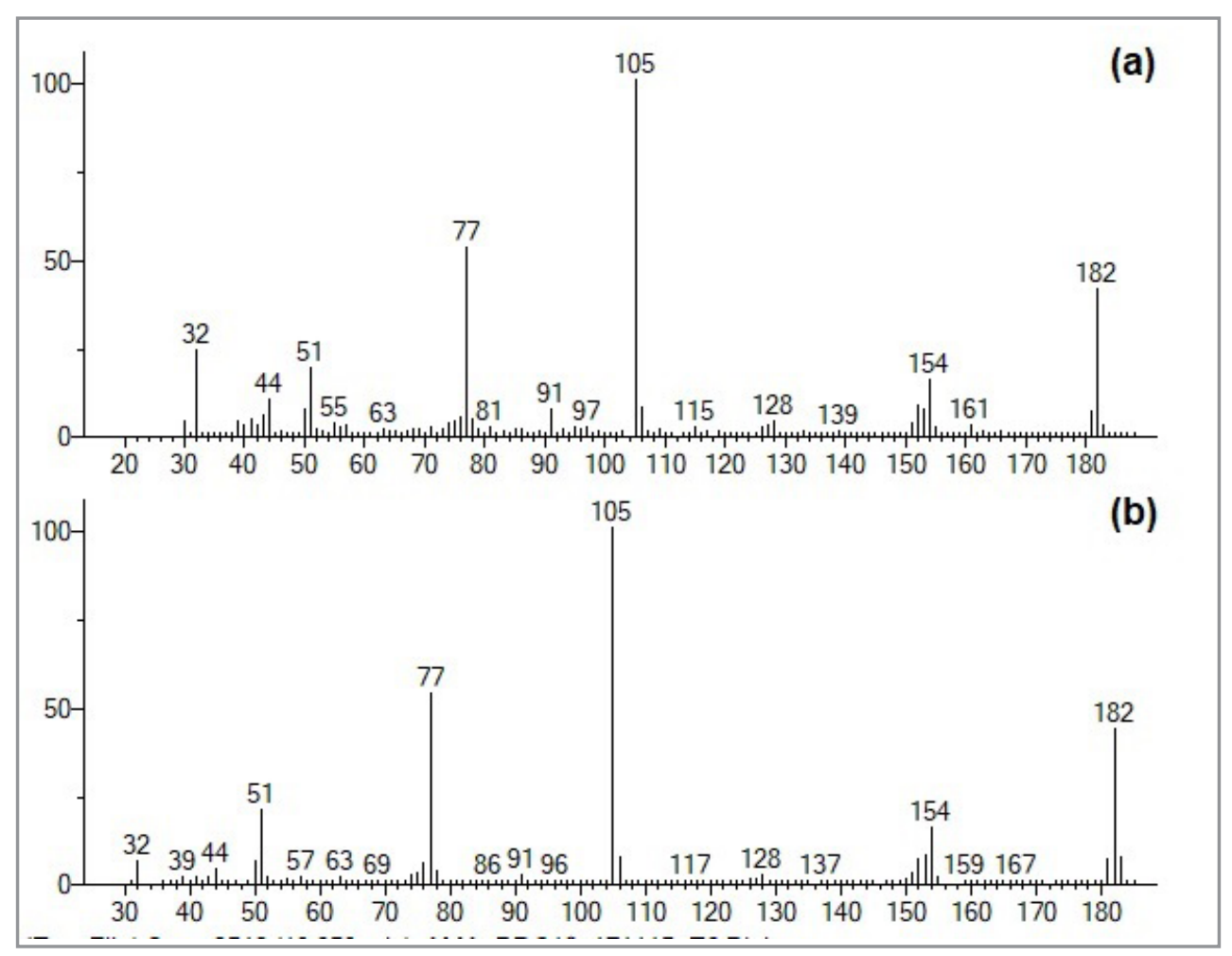

GC-MS spectra of benzophenone (retention time 19.255-19.258 min) in samples (a) BDC 1 and (b) BDC 2. 


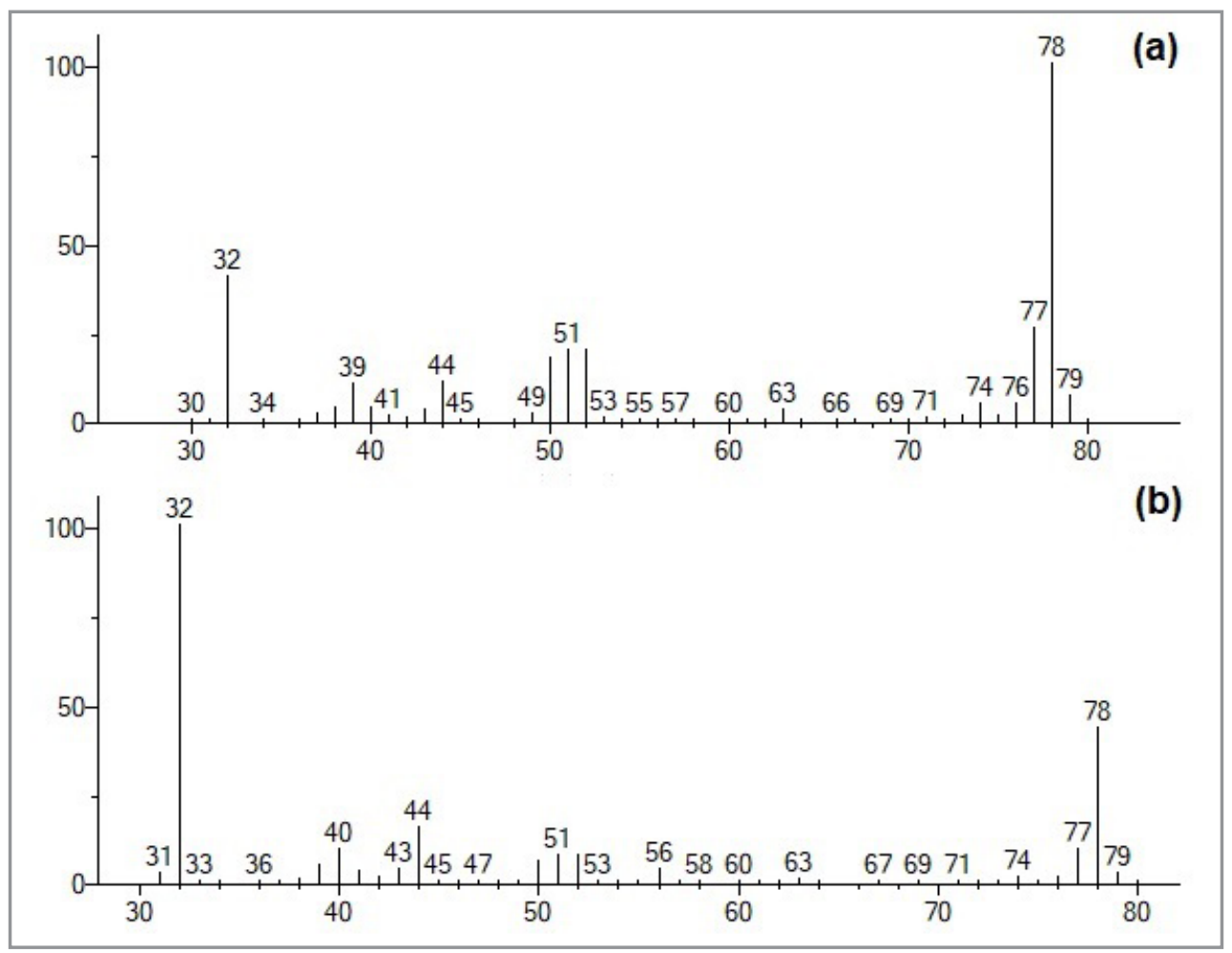

GC-MS spectra of benzene (retention time 2.231-2.248 min) in samples (a) BTC 1 and (b) BTC 2.

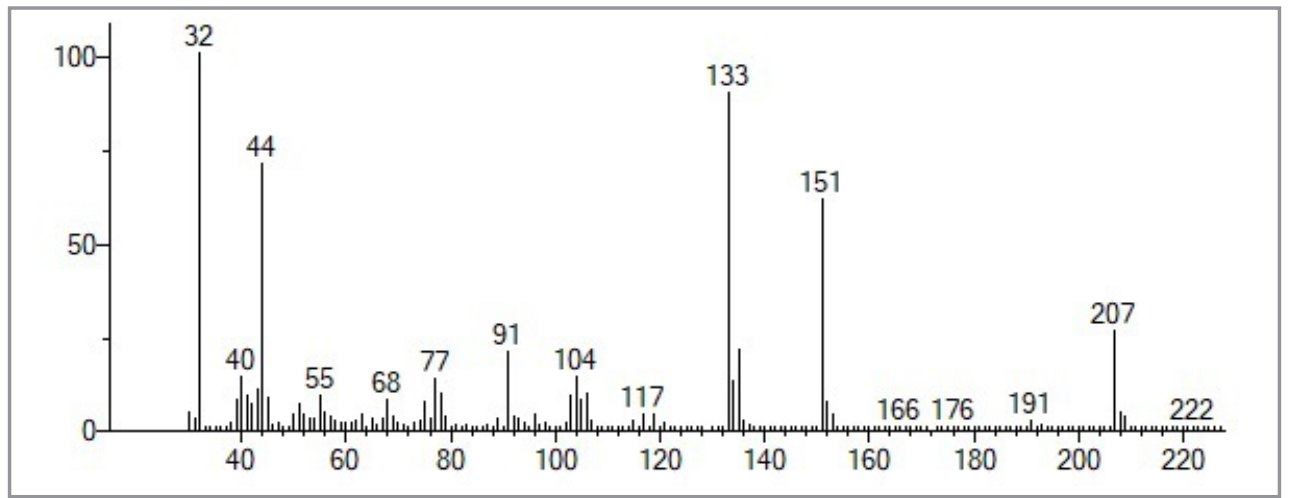

GC-MS spectra of 3-(3-Carboxy-4-hydroxyphenyl)-d-alanine (retention time $5.121 \mathrm{~min}$ ) in sample BTC 2.

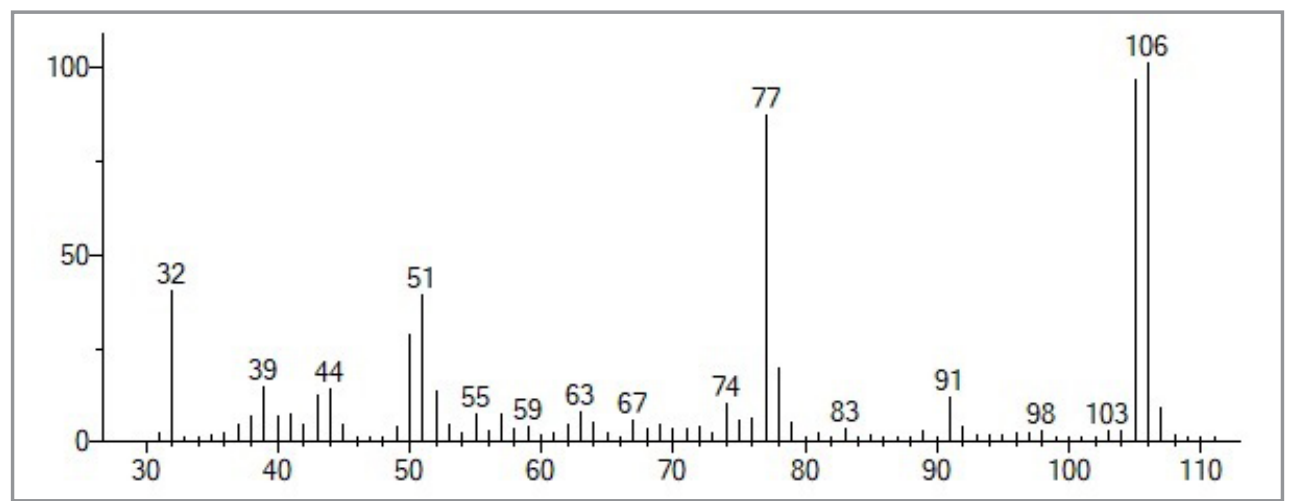

GC-MS spectra of benzaldehyde (retention time $6.237 \mathrm{~min}$ ) in sample (a) BTC 1. 


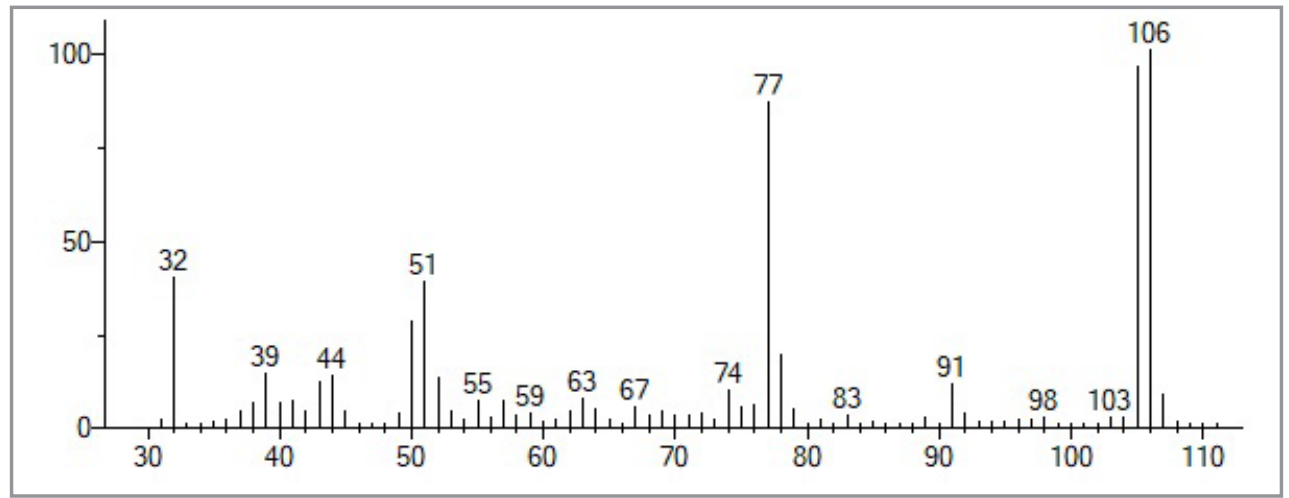

GC-MS spectra of phenol (retention time $6.460 \mathrm{~min}$ ) in sample BTC 1.

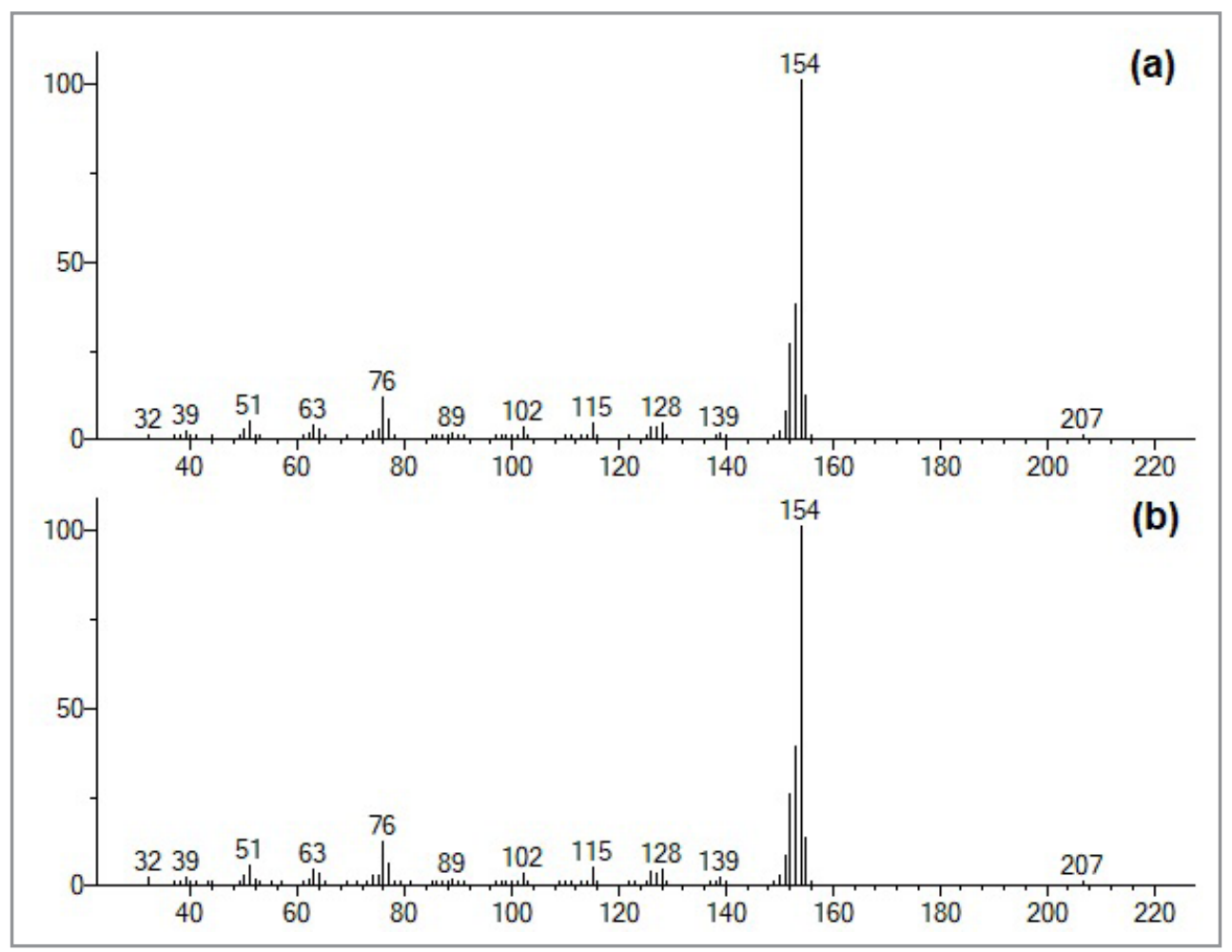

GC-MS spectra of biphenyl (retention time 13.809-13.813 min) in samples (a) BTC 1 and (b) BTC 2.

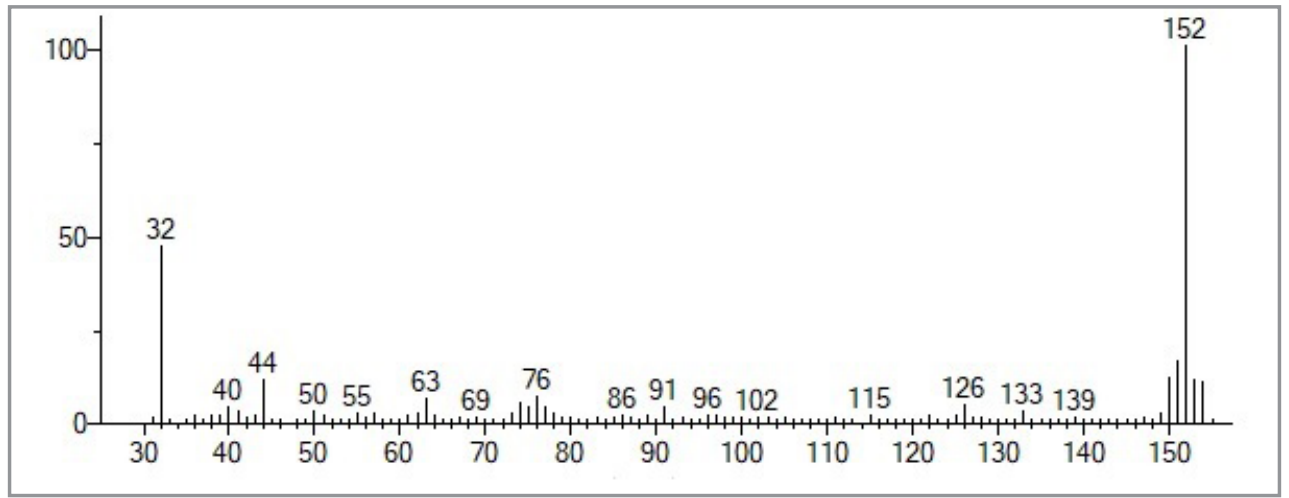

GC-MS spectra of acenaphthylene (retention time $15.347 \mathrm{~min}$ ) in sample BTC 1. 